\title{
Viabilidade Econômica da Produção de Eucaliptos no Rio Grande do Sul
}

\author{
Juliano Andre Pavan \\ Mestrado em Ciências Contábeis pela Universidade do Vale do Rio dos Sinos - \\ UNISINOS \\ Professor da Faculdade Anhanguera \\ Rua Paissandu, 1200. Passo Fundo/RS. CEP: 99010-033 \\ E-mail: juliano@grupopavan.com.br
}

Tiago Wickstrom Alves

Doutorado em Economia pela Universidade Federal do Rio Grande do Sul - UFRGS

Professor da Universidade do Vale do Rio dos Sinos - UNISINOS

Avenida Unisinos, 950. Bairro Cristo Rei. São Leopoldo/RS. CEP: 93022-000

E-mail:wickstrom.alves@gmail.com

Marcos Antonio de Souza

Doutorado em Controladoria e Contabilidade pela Universidade de São Paulo - USP

Professor da Universidade do Vale do Rio dos Sinos - UNISINOS

Avenida Unisinos, 950. Bairro Cristo Rei. São Leopoldo/RS. CEP: 93022-000

E-mail:marcosas@unisinos.br

\section{RESUMO}

Este estudo tem como objetivo analisar a viabilidade econômica da produção de eucaliptos no Rio Grande do Sul, atendendo a diferentes canais de comercialização. O estudo tem como base a estrutura de custos de produção da Aracruz (2005), os quais foram cotejados com os obtidos junto a EMATER/RS (2005) e complementados com dados da Empoflor. Após a mensuração dos custos calculou-se o Valor Presente Líquido e o Valor Presente Líquido Geral para os canais de energia, celulose, serraria e laminação por distância do produtor ao consumidor - de $50 \mathrm{~km} \mathrm{a} 400 \mathrm{~km}$. A produtividade geral foi determinada com base no software SisEucalipto, após simular a produtividade sob diferentes densidades, desbastes e período das rotações. Os resultados apontam que produzir eucaliptos para atender à geração de energia não traz viabilidade superior ao custo de oportunidade em nenhuma faixa de distância analisada. Produzir eucaliptos para atender à fabricação de celulose somente traz retorno superior ao custo de oportunidade da terra para o produtor que estiver a $50 \mathrm{~km}$ da fábrica. Já produzir eucaliptos direcionando para serraria ou laminação é viável até a faixa de distância de 350 km.

Palavras-chave: Custo de Produção. Eucaliptos. Viabilidade Econômica. 


\section{ABSTRACT}

This study aims to analyse the economic viability of the Eucalypitus production in Rio Grande do Sul, under different commercialization channels. The study is based (benchmark) on the cost structure of Aracruz (2005). These data were compared with Emater/RS (2005), and complemented with the ones from Empoflor. After obtaining the results for costs we computed the Net Discounted Value and the Net General Discounted Value for the energy, cellulose, sawmill, and blader channels for a range of distance that goes from 50 to $400 \mathrm{Km}$ between the producer and the consumer. In order to determine the general productivity we used the SisEucalipto software for the simulation of productivity under different densities, hews, and turnover (rotation) periods. The results indicate that production of Eucalyptus aiming at power generation is not economic feasible for all distances within the defined range. The production of Eucalyptus for application in cellulose is economically feasible only to distances up to 50 $\mathrm{km}$ from the mill. Finally, when aimed to sawmill and blader the economic viability of Eucalyptus production is achieved up to a distance of $350 \mathrm{Km}$.

Key Words: Production Cost. Eucalyptus. Economic Viability.

\section{INTRODUÇÃO}

O Rio Grande do Sul tem recebido investimentos significativos de empresas produtoras de celulose. Como exemplo cita-se: a expansão da fábrica da Aracruz em Guaíba, região metropolitana de Porto Alegre, com investimento estimado em $R \$ 4,9$ bilhões; a Votorantim Celulose e Papel com a construção de uma fábrica com capacidade de 1,3 milhão de toneladas por ano e investimentos estimados de US\$1,3 bilhão, para operar a partir de 2011 (INTELOG, 2008); e, ainda, a Stora Enso com investimentos de US\$ 900 milhões a US\$ 1 bilhão na construção de uma fábrica para produzir celulose e, de aproximadamente, US\$250 milhões na compra de terras na metade sul do Estado para plantar 100 mil hectares de árvores (Revista da Madeira, 2006).

Esses investimentos têm gerado diversas discussões, entre elas a questão do retorno para os produtores que aderirem à produção de eucaliptos. Assim, esse estudo objetiva colaborar com informação relativa ao retorno financeiro dessa atividade no Estado, a partir de uma análise conjunta de custos e otimização da produtividade - via simulação nos diferentes canais de comercialização. Ou seja, o objetivo dessa pesquisa 
é projetar a viabilidade econômica da produção de eucaliptos no Rio Grande do Sul atendendo os canais de energia, celulose, serraria e laminação.

Dado esse objetivo, o trabalho está estruturado, além dessa introdução, nas seguintes seções. Na seção um faz-se uma análise dos custos de produção. Toma-se como base os custos de produção obtidos junto a Aracruz Celulose, EMATER/RS e a Empoflor. A partir desses dados, elabora-se uma estrutura de custos. A seção dois trata da simulação. Para tanto, utilizou-se o software SisEucalipto para simular a produtividade sob diferentes densidades, desbastes e período das rotações, para a obtenção da melhor estrutura produtiva de forma a maximizar a produção. A seção três baseia-se nos dados das seções anteriores, pois é a que se destina a avaliar a rentabilidade da produção de eucaliptos. Nessa seção, calcula-se o Valor Presente Líquido (VPL) e o Valor Presente Líquido Geral (VPLG) da produção de eucaliptos no Rio Grande do Sul, dada a estrutura de custos proposta neste estudo e os resultados da simulação. Por fim, tem-se a conclusão.

\section{CUSTOS DE PRODUÇÃO}

Para estimar a estrutura dos custos totais de produção, foram comparados os itens que compõem os custos relatados pela Aracruz, EMATER/RS e Empoflor. Além disso, e com base em dados da EMBRAPA, agregaram-se outras atividades relacionadas com a produção de eucaliptos e que não constavam na estrutura de custos dessas três empresas. Para a mensuração do custo de oportunidade da terra, foram utilizados dados de valor de arrendamento obtidos junto a EMATER/RS. Na seqüência, cotou-se os valores dos bens e serviços que compunham a estrutura de custos definida, com base nos dados das referidas empresas ou nos preços praticados no mercado. Essa base de mercado foi utilizada nos casos de ausência da informação ou de excessiva dispersão dos preços obtidos com as empresas citadas. Esse processo de determinação da estrutura e custeio está descrito a seguir.

1. Roçada: A EMATER/RS não considera a execução desta atividade, partindo da premissa de que o terreno tem uma vegetação rasteira. A Aracruz relata um 
custo de $R \$ 85,00 /$ ha, com a utilização de uma hora de trator. A planta que disputa os nutrientes do solo com outras gramíneas pode ter seu desenvolvimento prejudicado. Por esta razão e para facilitar a execução do plantio, o custo de roçada é utilizado neste estudo.

2. Escarificação e fosfato: Escarificação ou subsolagem é o processo de rompimento da compactação do solo, sendo necessário, na maioria das vezes, para a facilitação do plantio. A EMATER/RS considera a necessidade de escarificação apenas na linha, o que geraria um custo de $R \$ 60,00 / h a$, desconsiderando a aplicação de fosfato em função de que ele é necessário apenas para solos mais arenosos, onde o nutriente fósforo $(P)$ é reduzido. $A$ Aracruz recomenda a escarificação na área total com a aplicação de $200 \mathrm{~kg}$ de fosfato/ha por hectare, alcançando um custo de $R \$ 324,20 /$ ha, sendo $R \$ 119,20$ de insumos e $R \$ 205,00$ de serviços. O fosfato mantém o crescimento das raízes e da inflorescência das sementes, favorecendo o processo de lignificação, sendo importante para a atividade da microflora e microfauna do solo (AMBIENTE BRASIL, 2005). Por essa razão, a sua aplicação foi levada em consideração neste planejamento.

3. Construção de estradas: A construção de estradas, além de facilitar o acesso, escoa a produção e reduz o risco de perda total da floresta em situações de incêndio. Segundo a EMBRAPA, a floresta deve ser dividida em quadras de 10 ha, com uma estrada de $6 \mathrm{~m}$ de largura entre as elas, cujo custo é de $\mathrm{R} \$$ 75,00/ha. No custo da EMATER/RS esta atividade não é levada em consideração, dado que o seu foco é o pequeno produtor. Como se considera importante a questão da prevenção em relação a incêndios, e tendo em vista a produção não só de pequenos produtores, optou-se pela inclusão desse custo.

4. Gradagem: A gradagem é o processo de uniformização do terreno, necessário quando executada a escarificação. Para esta atividade o custo da EMATER/RS é de $R \$ 50,00 /$ ha e o da Aracruz de $R \$ 60,00 /$ ha. Não sendo possível detectar elementos que justifiquem essa diferença, coletou-se o custo desse serviço com a Reflorestadora Nativa (2005), avaliado em $R \$ 70,00 /$ ha. No entanto, a empresa 
afirmou que se for áreas com mais de 10 hectares o custo se reduz para $R \$$ 60,00 . Dessa forma, optou-se por utilizar o custo de $R \$ 60,00 /$ ha.

5. Controle da formiga cortadeira: O formicida deve ser aplicado no plantio e após o corte da madeira, para que a brotação não seja obstruída pelas formigas. Essa atividade necessita de $8 \mathrm{~kg} / \mathrm{ha}$ de formicida, segundo dados da EMATER/RS e Aracruz, cujo preço apresentou variação de $4,51 \%$. Para dirimir a dúvida sobre qual utilizar, cotou-se o preço do formicida com a empresa Fertibras (2005), que informou um custo de $\mathrm{R} \$ 5,70$ o pacote de $500 \mathrm{~g}$ do formicida Mirex-S. Logo, o custo de $8 \mathrm{~kg}$ é de $\mathrm{R} \$ 91,20[(5,7 \times 2) \times 8]$. Esse valor é maior do que o fornecido pela Aracruz ( $R \$ 88,83$ ) e pela EMATER/RS ( $R \$ 85,00)$. Assim, adotou-se o custo de $\mathrm{R} \$ 88,83 /$ ha por ser um valor intermediário e também pelo fato de que na compra de uma quantidade maior o preço tende a ser menor.

6. Aplicação do calcário: A aplicação do calcário, necessária para reduzir a acidez do solo, não está listada nos custos da EMATER/RS, porém, a empresa defende que a incorporação deste insumo deve ser realizada se a análise de fertilidade do solo exigir. A Aracruz, todavia, recomenda a aplicação de $1.000 \mathrm{~kg} / \mathrm{ha}$ de calcário, com um custo total de $R \$ 110,62 /$ ha, sendo $R \$ 52,00$ de insumos e $R \$$ 58,62 de serviços.

Segundo a ANDA (1991), o excesso de acidez no solo não corrigido, reduz consideravelmente a produtividade. Desta forma, a aplicação de calcário foi levada em consideração conforme definido pela Aracruz.

7. Plantio com alinhamento de mudas: $O$ custo de $R \$ 520,00$ informado pela EMATER/RS corresponde a uma densidade de 2.083 [10.000 / (3 x 1,60)] mudas. Para essa empresa as espécies custam $R \$ 0,15(R \$ 320,00 / 2.083)$ cada unidade, por terem heterogeneidade tanto em termos fenótipos como genótipos. Os serviços de plantio apresentam um custo de $\mathrm{R} \$ 0,10(\mathrm{R} \$ 200,00 / 2.083)$ por espécie, por utilizar o sistema manual.

A Aracruz apresenta um custo de $\mathrm{R} \$ 468,97$, correspondente a uma densidade de 1.111 [10.000 / (3 x 3)] mudas. Cada espécie plantada custa $R \$ 0,24$ $(\mathrm{R} \$ 261,09 / 1.111)$ por ser clonada. Logo, o plantio terá um nível de homogeneidade 
maior, tendo benefícios em produtividade e qualidade da madeira. Para essa empresa os serviços de plantio têm um custo de $R \$ 0,19$ ( $R \$ 207,88 / 1.111)$ por utilizar o sistema mecanizado. Nota-se que o custo dos serviços do sistema de plantio mecanizado é superior ao do sistema de plantio manual. Isso pode ser justificado pelo tempo improdutivo gasto com manobras, regulagens e abastecimento da máquina (Fessel, 2003). No entanto, Stjernberg (1991), conclui que com o trabalho mecanizado do solo a produtividade dos trabalhadores envolvidos aumenta. Desse modo, o custo de plantio adotado neste estudo é o mecanizado com a implantação de mudas clonadas, conforme informado pela empresa Aracruz.

8. Adubação de arranque: Ambas as empresas recomendam $1 \mathrm{Kg}$ de adubo orgânico para cada planta, desde que o solo não apresente outras deficiências. No entanto, a EMATER/RS considera que a mão-de-obra das atividades plantar e adubar são as mesmas. Já a Aracruz, cujo custo é adotado neste estudo, relaciona a mão-de-obra da atividade plantar no valor de $\mathrm{R} \$ 68,62$ para uma densidade de 1.111 mudas. A necessidade de separação dos processos surge da execução do plantio de grande escala em prol da redução do tempo gasto.

9. Replantio com adubação $20 \%$ e $10 \%$ : O replantio ocorre porque algumas plantas não sobrevivem, podendo ser deficiência genética ou manuseio inadequado no plantio, entre outros fatores. A EMATER/RS apresenta uma mortalidade de $20 \%$ com a utilização de mudas tradicionais e a Aracruz uma mortalidade de 10\% com o plantio de mudas clonadas. Por estar definido anteriormente, no item 7, que o custo de plantio fornecido pela Aracruz é o utilizado, considerar-se o seu respectivo custo de replantio.

10. Aplicação do Herbicida pré-emergencial: $\mathrm{Na}$ estrutura de custos proposta pela EMATER/RS não aparece o controle a pragas e vegetais na atividade plantio. $A$ Aracruz recomenda a aplicação de quatro litros de herbicida pré-hemergencial aplicado em toda área, com um custo total (serviços e insumos) de $R \$$ 149,34/ha. Este custo é considerado neste estudo, pelo fato da aplicação de herbicida retardar o crescimento de pragas e vegetais que dificultariam 0 desenvolvimento da muda. 
11. Roçada manual na linha: A roçada é outra atividade não relacionada pela EMATER/RS. Por sua vez, a Aracruz considera o custo de roçada manual na linha plantada, no valor de $R \$ 67,00 /$ ha. Esta atividade não foi considerada uma vez que se estipulou a realização de uma capina química na linha.

12. Capina química na linha: Capina química é a eliminação de vegetais, realizada por meio da aplicação de herbicidas que, além de matá-los, pode impedir ou retardar o seu crescimento. A EMATER/RS não relacionou tal atividade. Já a Aracruz instituiu a aplicação de oito litros de herbicida Glifosato, com um custo de $R \$ 248,50 /$ ha entre insumos e serviços. A eliminação de vegetais por meio da capina química está considerada neste estudo.

13. Adubação de cobertura: $A$ adubação de cobertura, útil para reforçar a adubação de plantio, está considerada neste estudo. A EMATER/RS não relaciona essa atividade na sua estrutura de custos. Já a Aracruz recomenda a aplicação de 126 gramas de adubo composto para cada planta, resultando em um custo de $\mathrm{R} \$ 192,83$ /ha de insumos e serviços. Como medida mais conservadora, adotouse neste estudo a adubação de cobertura conforme estabelecido pela Aracruz.

14. Adubação de cobertura: $1^{\circ}$ ano - para a atividade tratos culturais, tanto a EMATER/RS quanto a Aracruz recomendam a aplicação de 2 toneladas de adubo orgânico para cada hectare, aplicado na linha ainda no primeiro ano. Nesta atividade tem-se uma variação de 2,78\% entre o custo da EMATER/RS e o da Aracruz, de $R \$ 180,00$ e $R \$ 185,95$ respectivamente. Optou-se pelo custo da Aracruz, pois todos os tratos culturais tratados a seguir também fazem parte da sua estrutura incorporada no estudo.

15. Capina química entre linha no $1^{\circ}$ ano ou roçada: EMATER/RS não orçou esta atividade. A Aracruz sugere a aplicação de 8 litros de herbicida Glifosato, aplicados ainda no primeiro ano, com um custo de serviços e insumos no valor de $\mathrm{R} \$ 172,00$. Novamente por questão de conservadorismo adotou-se o valor informado pela Aracruz.

16. Capina química entre linha no $2^{\circ}$ ano ou roçada: Idem ao item 15 , sendo que sua aplicação deve ser realizada no segundo ano. 
17. Assistência por hectare/ano: EMATER/RS não relacionou esta atividade afirmando que o produtor tem acesso a informativos e cursos gratuitos que difundem a técnica de plantio, e que para projetos de pequena escala o produtor pode obter assistência técnica gratuita da EMATER/RS. A Aracruz computa um custo de assistência técnica anual de $R \$ 57,40 /$ há, assumido nesse estudo.

Procurando relacionar todos os custos incidentes na produção de eucaliptos, aborda-se, a seguir, as atividades não consideradas por ambas as empresas mas que são incidentes no processo e, portanto, assumidas nesse estudo. As estimativas referem-se ao custo de desrama e desbrota, corte, descasca e baldeio, carregamento e transporte, do custo de oportunidade da terra e da determinação do fluxo de caixa residual.

18. Desrama e desbrota: A desrama consiste na retirada dos galhos que estão brotando no tronco, e deve ser realizada nos $1^{\circ}$ e $2^{\circ}$ anos, sendo que esta atividade é realizada quando a produção atender os canais de serraria e laminação. Já a desbrota é a retirada de brotos excessivos que surgem no toco quando a madeira é cortada, iniciando assim a segunda rotação. Esta atividade não é considerada pela EMATER/RS e tampouco pela Aracruz.

No entanto, segundo a EMBRAPA (2005), o custo de desrama e desbrota para um hectare de terra é $R \$ 93,00$ ( $R \$ 18,60$ homen/dia $\times 5$ dias) para a densidade de 2.000 mudas; $R \$ 74,40$ ( $R \$ 18,60$ homen/dia $\times 4$ dias) para a densidade de 1.666 mudas, e $R \$$ 55,80 ( $\mathrm{R} \$ 18,60$ homen/dia $\times 3$ dias) para as densidades de 1.333 e 1.111 mudas plantadas. O custo de desbrota é necessário para todos os canais que tiverem mais do que um ciclo, e o custo de desrama para o a produção que se destina à serraria e a laminação.

19. Corte, descasca e baldeio: Os custos com o corte, a descasca e o baldeio foram cotados com a empresa Empoflor (2005). A justificativa para a escolha da cotação nesta empresa está na especialidade e na abrangência dos serviços que presta no estado do Rio Grande do Sul. O custo apresentado pela empresa para cortar um metro cúbico de eucaliptos é de $R \$ 6,76$, sendo ele incidente na realização do desbaste ou no corte final da floresta. A execução da descasca, 
necessária quando a produção atender a fabricação de celulose, está cotada em $\mathrm{R} \$ 6,38 / \mathrm{m}^{3}$. Já o baldeio, que se refere ao empilhamento, normalmente em beira de estrada, apresenta um custo de $\mathrm{R} \$ 4,55 / \mathrm{m}^{3}$.

Essas operações são realizadas com o auxílio de equipamentos específicos para este tipo de atividade, sendo que nesse estudo não se considerou a aquisição das máquinas e sim a terceirização dos serviços. A atividade corte se refere à retirada dos galhos e da decepa da árvore para, na seqüência, executar a tiragem da casca; o direcionamento para o empilhamento é denominado baldeio. Estes custos têm incidência na realização dos desbastes e no corte final e são complementados pelo custo de carregamento e transporte.

20. Carregamento e transporte: O custo do transporte é um dos fatores mais relevantes no planejamento florestal, pois, dependendo da distância entre a floresta e a empresa compradora, o retorno do investimento pode ser inviabilizado. O custo desta atividade foi cotado com a Empoflor (2005), pela sua especialidade e tradição no ramo.

O produtor que contratar o serviço de carregamento e transporte pagará o deslocamento, a ida e a volta da equipe que realiza o serviço. A cotação do custo tem diferenciação se a estrada for pavimentada ou não. O custo de transporte de estrada pavimentada diminui à medida que aumenta a distância percorrida até $150 \mathrm{~km}$. A partir dessa distância se mantém aproximadamente constante em $R \$ 0,09540 / \mathrm{km}$. O mesmo ocorre com a estrada não pavimentada. $O$ transporte da madeira realizado em estrada sem pavimentação tem um custo mais elevado. Entre os fatores determinantes dessa diferenciação destaca-se a taxa acelerada de depreciação do veículo e o tráfego lento do transporte nesse tipo de estrada.

Dado que, em média, o deslocamento é realizado, parte em estrada pavimentada e parte em estrada não pavimentada e, sendo que grande parte desse deslocamento ocorre em estrada com pavimentação, definiu-se que o custo de carregamento e transporte até a sede compradora terá sempre $10 \mathrm{~km}$ de estrada sem pavimentação e o restante ocorrendo em estrada pavimentada. 
21. Custo de Oportunidade da Terra: Outro fator que necessita ser considerado na análise da viabilidade econômica é o custo de oportunidade da terra, ou seja, quanto o investidor vai deixar de ganhar com um uso alternativo da terra por ter optado pelo investimento florestal. A pesquisa parte da premissa de que o investidor possui terra própria; logo, ele poderia receber recursos decorrentes do seu arrendamento. Esse recurso que ele está deixando de receber por decidir produzir eucaliptos foi considerado como seu custo de oportunidade.

Considerando que o valor de arrendamento de terra no Rio Grande do Sul é determinado em sacas de soja, obteve-se o número de sacas de soja por hectare/ano, em diversas regiões do Estado. Eles foram obtidos com as unidades regionais da EMATER/RS, em termos de média praticada em cada região para plantação de cereais, referenciando desta forma o custo de arrendamento de um hectare de terra plana ou de serrado. A média geral da quantidade de sacas praticada nas regiões do Rio Grande do Sul é de oito sacas $(60 \mathrm{~kg})$ de soja por ha/ano, com um desvio padrão de 1,25.

Assim, considerou-se 8 sacas de soja por ha/ano como base para o custo de oportunidade. Porém, como o preço da soja oscila de mês a mês, calculou-se a sazonalidade dos preços da soja de janeiro de 2000 a maio de 20051 através do Índice de Estacionalidade. O cálculo dos Índices Estacionais de preços foi efetuado utilizando a fórmula proposta por Hoffmann et al. (1991) e ajustado com a fórmula de Karmel e Polasek (1973). A série dos preços apresentou os seguintes índices mensais: Janeiro 105,42; Fevereiro 101,21; Março 96,28; Abril 88,65; Maio 84,24; Junho 90,05; Julho 95,99; Agosto 97,70; Setembro 103,16; Outubro 109,91; Novembro 116,47; Dezembro 110,90 .

Tomou-se a cotação da saca de soja do mês de agosto de 2005, no valor de $\mathrm{R} \$$ 30,00 , ajustou-se à média acrescentando 2,3\% (100\% - 97,70\%) ficando em $R \$ 30,69$. Portanto, o custo de arrendamento anual utilizado é de $\mathrm{R} \$ 245,52$ ( $\mathrm{R} \$ 30,69 \times 8$ sacas) ha/ano.

22. Fluxo de caixa residual: Considerou-se que após a exploração florestal o investidor deveria deixar a terra em condições para a produção de qualquer outra

\footnotetext{
1 Valores correntes obtidos junto a Fundação Getúlio Vargas - FGV, 2005.
} 
atividade agrícola. Sendo assim, após a liquidação do investimento seria necessário remover os tocos das árvores. Esses tocos, acoplados com raízes, poderiam ser vendidos para abater o custo do destocamento. Porém, conforme EMBRAPA (2005), o valor de venda desses tocos é de $R \$ 5,00 \mathrm{o} \mathrm{m}^{3}$, o que não compensa o custo de transporte. Esse fato tem feito com que os produtores que praticam a destoca queimem os resíduos. Dessa forma, não se considerou como receita no fluxo de caixa residual a venda dos tocos, mas apenas o seu custo de remoção.

A remoção dos tocos, denominada destoca, é orçada por hora máquina utilizada. A cotação do preço desse serviço foi obtida com a EMPOFLOR (2005), por ter especialidade no ramo e ser a empresa que realiza essa atividade para a Aracruz e para seus terceirizados no Rio Grande do Sul. Para remover os tocos de uma floresta de 21 anos, utilizam-se 25 horas de escavação cotadas a $R \$ 100,00$ a hora, totalizando $R \$ 2.500,00$. O custo de destoca não varia pela densidade e sim pela idade da floresta, pois para a destoca é utilizada uma escavação generalizada na terra. Portanto, o tempo de remoção por árvore não varia, dado que as escavações serão realizadas a uma mesma profundidade.

\subsection{Resumo das informações de custos apresentadas e estrutura adotada}

Como se verificou no decorrer desta seção, existem diferenças de custos entre a EMATER e a ARACRUZ para a produção de eucalyptus. Há, também, atividades que não foram informadas e que foram acrescidas com base na EMBRAPA e na EMPOFLOR. Assim, a estrutura final, proposta neste estudo contempla informações das empresas Aracruz, Emater, Embrapa e Empoflor.

A Tabela 1 resume as informações descritas anteriormente. Acrescenta-se nessa tabela o cálculo de custos para as densidades de $1.111,1.666$ e 2.038 mudas. A especificação da determinação de tais densidades encontra-se na seção seguinte. 
Tabela 1: Custos totais por densidade para produção de eucaliptos

\begin{tabular}{|c|c|c|c|}
\hline ATIVIDADES & \multicolumn{3}{|c|}{ CUSTO EM R\$ POR DENSIDADE } \\
\hline Preparo do terreno (i) & 2.038 & 1.666 & 1.111 \\
\hline 1- Roçada (Aracruz) & 85,00 & 85,00 & 85,00 \\
\hline 2- Escarificação e fosfato (Aracruz) & 324,20 & 324,20 & 324,20 \\
\hline 3- Construção estradas (EMBRAPA) & 75,00 & 75,00 & 75,00 \\
\hline 4- Gradagem (Aracruz) & 60,00 & 60,00 & 60,00 \\
\hline Sub - total & 544,20 & 544,20 & 544,20 \\
\hline \multicolumn{4}{|l|}{ Plantio (ii) } \\
\hline 5- Controle da formiga cortadeira (Aracruz) & 88,83 & 88,83 & 88,83 \\
\hline 6- Aplicação do calcário (Aracruz) & 110,62 & 110,62 & 110,62 \\
\hline 7- Plantio com realinhamento de mudas (Aracruz) & 860,27 & 703,24 & 468,97 \\
\hline 8- Adubação de arranque (Aracruz) & 246,69 & 201,66 & 134,48 \\
\hline 9- Replantio com adubação $20 \%$ e $10 \%$ (Aracruz) & 102,89 & 84,11 & 56,09 \\
\hline 10- Aplicação do Herbicida pré-emergencial (Aracruz) & 149,34 & 149,34 & 149,34 \\
\hline 11- Roçada manual na linha & 0 & 0 & 0 \\
\hline 12- Capina química na linha (Aracruz) & 248,5 & 248,5 & 248,5 \\
\hline 13-Adubação de cobertura (Aracruz) & 353,72 & 289,16 & 192,83 \\
\hline Sub - total & $2.160,86$ & $1.875,46$ & $1.449,66$ \\
\hline \multicolumn{4}{|l|}{ Tratos culturais } \\
\hline \multicolumn{4}{|l|}{ Do 1a ano - 1ำ rotação (iv) } \\
\hline 14- Adubação de cobertura - 1a ano (Aracruz) & 341,10 & 278,84 & 185,95 \\
\hline 15- Capina química entre linha $1^{\circ}$ ano ou roçada (Aracruz) & 172,00 & 172,00 & 172,00 \\
\hline Sub - total & 513,10 & 450,84 & 357,95 \\
\hline \multicolumn{4}{|l|}{ Do $2^{\circ}$ ano - $1^{\circ}$ rotação (iv) } \\
\hline 16- Capina química entre linha $2^{\circ}$ ano ou roçada (Aracruz) & 172,00 & 172,00 & 172,00 \\
\hline 18- Desrama $2^{\circ}$ ano (EMBRAPA) & 0,00 & * 74,40 & 55,80 \\
\hline 18- Desrama $2^{\circ}$ ano (EMBRAPA) & 0,00 & * 74,40 & 55,80 \\
\hline Sub - total & 172,00 & 320,80 & 283,60 \\
\hline \multicolumn{4}{|l|}{ Do $1^{\circ}$ ano $-2^{\circ}$ e $3^{\circ}$ rotação } \\
\hline 5- Controle da formiga cortadeira (Aracruz) & 88,83 & 88,83 & 21,16 \\
\hline 14- Adubação de cobertura - 10 ano (Aracruz) & 341,10 & 278,84 & 95,75 \\
\hline 15- Capina química entre linha $1^{\circ}$ ano ou roçada (Aracruz) & 172,00 & 172,00 & 48,28 \\
\hline 18- Desbrota (EMBRAPA) & 93,00 & 74,40 & 22,46 \\
\hline Sub - total & 694,93 & 614,07 & 187,65 \\
\hline \multicolumn{4}{|l|}{ Do $2^{\circ}$ ano $-2^{\circ}$ e $3^{\circ}$ rotação } \\
\hline 16- Capina química entre linha $2^{\circ}$ ano ou roçada (Aracruz) & 172,00 & 172,00 & 172,00 \\
\hline 18- Desbrota $2^{\circ}$ ano (EMBRAPA) & 93,00 & 74,40 & 22,46 \\
\hline 18- Desrama $2^{\circ}$ ano (EMBRAPA) & 0,00 & * 74,40 & 22,46 \\
\hline 18- Desrama $2^{\circ}$ ano (EMBRAPA) & 0,00 & * 74,40 & 22,46 \\
\hline Sub - total & 265,00 & 395,20 & 239,38 \\
\hline Total & $4.522,09$ & $4.200,57$ & $3.062,44$ \\
\hline \multicolumn{4}{|l|}{ Outros custos } \\
\hline 17- Assistência Técnica por hectare/ano (iii) (Aracruz) & 57,40 & 57,40 & 57,40 \\
\hline 19- Corte $\mathrm{m}^{3}$ (vi) (Empoflor) & 6,76 & 6,76 & 6,76 \\
\hline 19- Descasca $\mathrm{m}^{3}$ (vi) ${ }^{\star \star}$ (Empoflor) & 6,38 & 6,38 & 6,38 \\
\hline 19- Baldeio $\mathrm{m}^{3}$ (vi) (Empoflor) & 4,55 & 4,55 & 4,55 \\
\hline 20- Transporte $\mathrm{m}^{3}$, deslocamento de 0-50 km (vii) (Empoflor) & 7,42 & 7,42 & 7,42 \\
\hline 21- Custo de oportunidade anual da terra (EMATER/RS) & 245,52 & 245,52 & 245,52 \\
\hline 22- Destoca na liquidação do projeto (viii) (Empoflor) & 2.500 & 2.500 & 2.500 \\
\hline
\end{tabular}


Fonte: Dados da pesquisa

* A produção para atender o canal de celulose não utiliza desrama.

** Só precisa descascar a produção com destino a celulose.

Referência entre parêntesis representa a instituição que foi determinante na definição do item.

$\mathrm{Na}$ determinação dos outros custos, identifica-se o custo de assistência técnica, o custo de oportunidade da terra e o custo de destoca com comportamento fixo por hectare, não variando por unidade plantada. No entanto, as atividades de corte, descasca, baldeio e transporte, variam por $\mathrm{m}^{3}$ produzido em cada hectare.

\section{PRODUTIVIDADE}

A produtividade da floresta de eucaliptos foi obtida via simulação, utilizando-se o software SisEucalipto2 que se destina basicamente à simulação do crescimento e produção de reflorestamentos de eucalyptus grandis. É um programa flexível, uma vez que a utilização de vários parâmetros proporciona uma infinidade de situações.

Por meio de um método interativo o usuário fornece os dados necessários para a realização dos cortes, os quais implicam não somente na produção gerada, mas também em um impacto no crescimento do povoamento remanescente. A partir de um catálogo de produtos definido pelo usuário, o programa pode dividir o volume de madeira resultante dos desbastes e do corte final em volume por classes de utilização industrial como energia, celulose, serraria e laminação, considerando o diâmetro e o comprimento das toras.

A variedade grandis foi fixada como a variedade a ser analisada, em função de ser uma espécie com sensibilidade média a geadas e secas, e por ser comercializada para os canais de serraria, de laminação, de celulose e de energia (URCAMP, 2005).

As informações necessárias para a simulação do software e os condicionantes determinados para a geração da produtividade, são:

2 Os softwares SisPinus e SisEucalipto, ambos desenvolvidos pela EMBRAPA, "ajudaram a incrementar a produtividade florestal brasileira (...). O SisPinus, mais antigo, em 2004 já era utilizado por cerca de 150 empresas e instituições da Argentina, Chile, Paraguai, Cuba e Estados Unidos. No Brasil, o sistema vem sendo aplicado em mais de $75 \%$ da área plantada com pinus. O retorno para o país é estimado em mais de R $\$ 46$ milhões por ano" Alle (2007). 
a) Índice de sítio: É a média da altura dominante que as árvores conquistam na região plantada. Segundo o inventário florestal gaúcho realizado em 2001, a altura dominante das florestas plantadas de eucaliptos no Rio Grande do Sul é 28,3 metros. No entanto, segundo a EMBRAPA, com a utilização de mudas clonadas a altura dominante atinge $\mathbf{3 5}$ metros de altura. Para a Aracruz a altura dominante é de 33 metros. Considerou-se a altura de 33 metros como índice de sítio da floresta em função de ser um valor intermediário entre o inventário florestal e o indicado pela EMBRAPA.

b) Diâmetros aceitos para cada canal: A concentração da produtividade em canais de comercialização recebe influência do diâmetro e do comprimento aceito nas indústrias de transformação da madeira. Para o canal de energia o diâmetro deve situar-se em até $40 \mathrm{~cm}$; para o de celulose, o diâmetro deve situar-se entre 8 e $40 \mathrm{~cm}$; para cerraria, entre 15 e $50 \mathrm{~cm}$; e laminação, entre 25 e $50 \mathrm{~cm}$; com 1,2m, $4 \mathrm{~m}$ e 1,35m de comprimento mínimo, respectivamente (EMBRAPA, 2005).

c) Dado que quanto maior o diâmetro maior o preço comercializado, então a tora que possui um diâmetro acima de $25 \mathrm{~cm}$ e um comprimento mínimo de $1,35 \mathrm{~m}$, deve ser direcionada para o canal de laminação para aumentar a receita no fluxo de caixa.

d) Vida útil da plantação: Por recomendação da EMBRAPA e por limitação do software, utilizou-se para determinar a vida útil da floresta o parâmetro de 40 anos, sendo este o tempo máximo aceito em um planejamento florestal para não causar redução na qualidade da madeira.

e) Densidade: Foi simulada (para cada canal de comercialização) conforme as categorias: (i) 1.111 mudas com espaçamento de $3 \mathrm{~m} \times 3 \mathrm{~m}$; (ii) 1.333 mudas com espaçamento de $3 \mathrm{~m} \times 2,5 \mathrm{~m}$; (iii) 1.666 mudas com espaçamento de $3 \mathrm{~m} \times 2 \mathrm{~m}$; (iv) 2.038 mudas com espaçamento de $3 \mathrm{~m} \times 1,6 \mathrm{~m}$; (v) 2.500 mudas com espaçamento de $2,5 \mathrm{~m} \times 1,6 \mathrm{~m}$.

f) Desbaste: Simulou-se a realização de desbastes, no período do planejamento, em escalas de $10 \%, 20 \%, 30 \%, 40 \%, 50 \%, 60 \%, 70 \%, 80 \%, 90 \%$ da base. 
g) Ciclos de corte: Procurando definir a época em que devem ser realizadas as rotações, efetuou-se uma simulação de produtividade. Na simulação informou-se o índice de sítio de 33 metros, uma densidade de 2.038 mudas clonadas com sobrevivência de $99 \%$ e a idade do planejamento de 21 anos. O resultado pode ser observado na Figura 1.

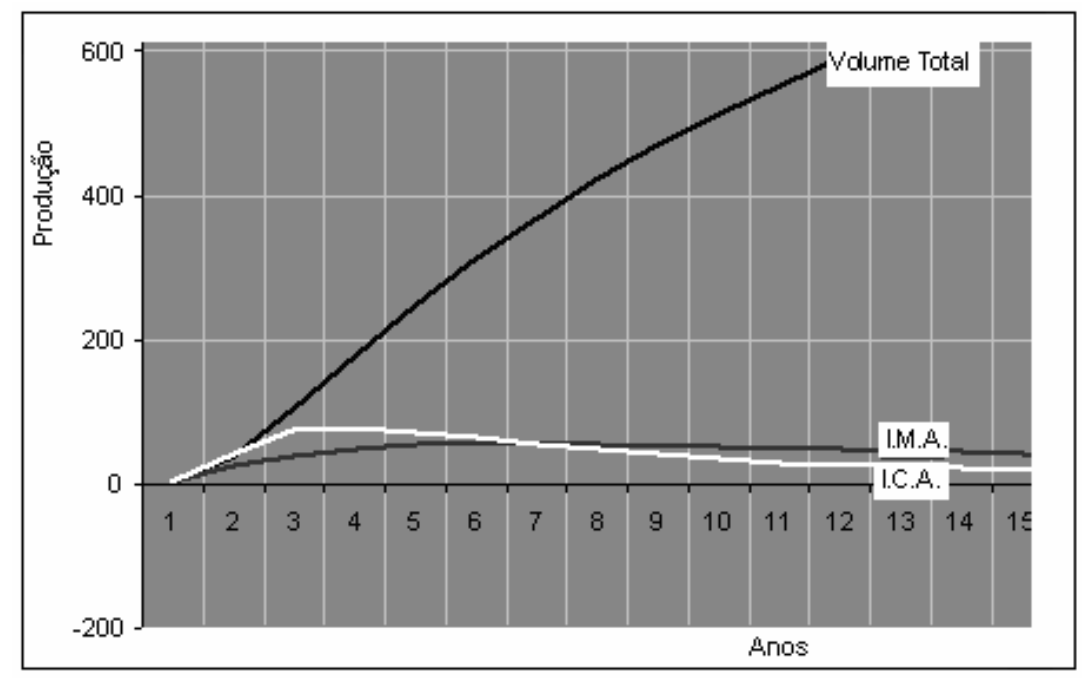

Figura 1: Época da rotação da produção de eucaliptos Fonte: Dados da pesquisa

A linha mais escura (Volume Total) é a produtividade em $\mathrm{m}^{3}$ que será ganha ao longo dos anos. A linha de tonalidade intermediária é o Incremento Médio Anual - IMA em $\mathrm{m}^{3}$. A linha mais clara é o Incremento Corrente Anual - ICA em $\mathrm{m}^{3}$. Observa-se que a floresta demora quatro anos para produzir $200 \mathrm{~m}^{3}$, necessitando de sete anos para produzir $400 \mathrm{~m}^{3}$, doze anos para produzir de $600 \mathrm{~m}^{3}$, e de 21 anos para produzir $800 \mathrm{~m}^{3}$.

A época de cortar a floresta e iniciar a nova rotação é quando o incremento corrente anual cruza o incremento médio anual, pois, a partir desse ponto a produtividade corrente é menor do que a média dos anos. Portanto, a idade ótima para a rotação da plantação de eucaliptos é de sete anos.

A densidade da floresta interfere sensivelmente na idade da rotação. Se a densidade for maior a época da rotação ocorre antes. Por sua vez, se a densidade for menor a época da rotação ocorre mais tarde. Cada densidade tende a concentrar a 
produtividade em um determinado diâmetro, atendendo com mais exclusividade um canal de comercialização especifico. A idade de rotação, em decorrência da densidade, gerou um desvio padrão de cinco meses.

Segundo a Aracruz (2005), as rotações não devem exceder a três períodos, pois, a cada corte perde-se $10 \%$ de produtividade. Sendo assim, este planejamento considera três rotações de 7 anos cada, determinando, desta forma, a vida útil da floresta de 21 anos para as modalidades de energia, celulose, serraria e laminação. Souza (2001), também confirma a realização de três rotações, como resultado da pesquisa realizada no estado de Minas Gerais, determinando o momento ótimo de substituição da floresta de eucaliptos.

A seguir são apresentados os resultados das simulações, por canal de comercialização.

\subsection{Canal de energia}

As simulações realizadas para otimizar a produtividade no canal de energia geraram melhores resultados com a densidade de 2.038 mudas em espaçamento $3 \mathrm{~m} \mathrm{x}$ $1,6 \mathrm{~m}$ e com a realização de três rotações de sete anos cada uma. A técnica de desbastes durante as rotações não apresentou resultados satisfatórios para este segmento.

$\mathrm{Na}$ simulação, informou-se uma sobrevivência de $100 \%$ do plantio, pois, na estimativa dos custos considerou-se a realização da atividade de replantio. No entanto, ocorre uma mortalidade natural das árvores influenciada pela disputa da fotossíntese e nutrientes do solo. Sendo assim, no ano sete da primeira rotação a população da floresta será de 2.008 árvores, 30 árvores a menos do que a densidade plantada no ano zero.

O volume total de madeira produzida corresponde ao somatório do incremento corrente anual - ICA de todos os anos. O ICA é a quantidade agregada em $\mathrm{m}^{3} \mathrm{em}$ cada ano. Já o incremento médio anual - IMA, é a média aritmética do volume total produzido com a idade da floresta, obtendo-se na primeira rotação $377,60 \mathrm{~m}^{3}$ de madeira, $339,80 \mathrm{~m}^{3}$ na segunda e $306,10 \mathrm{~m}^{3}$ na terceira. A cada corte perde-se $10 \%$ de 
produtividade, influenciada pela redução do número de árvores ao longo dos anos e pela perda de capacidade produtiva da planta quando submetida ao corte raso.

\subsection{Canal de celulose}

Para esta simulação ajustou-se o sistema para que toda a madeira com diâmetro de $8 \mathrm{~cm}$ a $40 \mathrm{~cm}$, e com um comprimento a partir de $1,20 \mathrm{~m}$, fosse destinada à fabricação de celulose. As madeiras que não alcançassem este diâmetro ou este comprimento mínimo seriam destinadas à geração de energia.

Os resultados indicaram que para otimizar a produtividade para a fabricação de celulose, se deveria ter uma densidade de 1.666 mudas, espaçamento $3 \mathrm{~m} \times 2 \mathrm{~m}$ com a realização de três rotações de sete anos cada uma. A técnica de desbastes durante as rotações também não apresentou resultados satisfatórios para este segmento. Ressalta-se que esta densidade é a recomendada pela EMATER/RS e a não realização do desbaste, para esta modalidade, é recomendado pela Aracruz.

Verificou-se que o incremento corrente $\left(\mathrm{em}^{3}\right)$ permanece maior do que o incremento médio em cada ano, justificando ganho de produtividade. Porém, há uma redução do incremento corrente a cada rotação. Na primeira rotação, produzir-se-á $342 \mathrm{~m}^{3}$ de madeira, sendo destinado $323,10 \mathrm{~m}^{3}$ para a fabricação de celulose e $18,9 \mathrm{~m}^{3}$ para a geração de energia por terem um diâmetro menor que $8 \mathrm{~cm}$ e um comprimento inferior a 1,20 metros.

\subsection{Canal de serraria}

Ajustou-se o sistema para que todas as toras com diâmetro de $15 \mathrm{~cm}$ a $50 \mathrm{~cm}$ e com um comprimento a partir de $2,4 \mathrm{~m}$ fossem direcionadas para o beneficiamento em serrarias. As madeiras que não atendessem estas medidas, exclusivas da serraria, mas que possuíssem de $8 \mathrm{~cm}$ a $40 \mathrm{~cm}$ de diâmetro e um comprimento mínimo de 1,2m, poderiam ser destinadas para a fabricação de celulose. Já aquelas que não atendessem estas especificações seriam destinadas à geração de energia. Os resultados apontaram que para otimizar a produtividade nas especificações do canal de serraria, necessitava-se deixar a floresta mais do que sete anos em cada ciclo. 
Testou-se então um ciclo de quatorze anos e um ciclo de sete anos, não obtendo resultados compensadores, pelo fato da produtividade do ciclo de sete anos concentrarse nas especificações do canal de celulose.

Dessa forma, estimou-se a produtividade concentrada em dois ciclos, sendo o primeiro de dez anos e o segundo de onze anos. Estas idades das rotações com uma densidade de 1.666 mudas, espaçamento $3 \mathrm{~m} \times 2 \mathrm{~m}$, apresentaram os melhores resultados para otimizar a produtividade no canal de serraria. A técnica de desbastes durante as rotações também não apresentou resultados satisfatórios para este segmento.

Verificou-se, ainda, que o incremento corrente anual de madeira no nono ano foi de $45,5 \mathrm{~m}^{3}$, e que é menor do que o incremento médio anual que foi de $48,6 \mathrm{~m}^{3}$. Isso significa que a partir deste ano a floresta não proporciona ganho em produtividade, mas aumento de diâmetro nas toras.

Analisando o volume das árvores removidas, a primeira rotação de dez anos poderá proporcionar $479,10 \mathrm{~m}^{3}$ de madeira, sendo $311,90 \mathrm{~m}^{3}$ para serraria, $144,50 \mathrm{~m}^{3}$ para a fabricação de celulose e $22,70 \mathrm{~m}^{3}$ para a geração de energia. Por sua vez, a segunda rotação poderá produzir $512,60 \mathrm{~m}^{3}$ de madeira, sendo aceito $343,90 \mathrm{~m}^{3}$ para o beneficiamento de serrarias, $146,10 \mathrm{~m}^{3}$ para o canal de celulose e $22,60 \mathrm{~m}^{3}$ para o canal de energia. Esta rotação apresentou resultados mais significativos quanto à maximização da produtividade da madeira para o canal de serraria.

Oliveira et al. (2002) concluíram em sua pesquisa que o melhor ciclo para ganhar diâmetro é o de dez anos, desbastando $70 \%, 80 \%, 90 \%$ ou $100 \%$. Esses resultados condizem com a simulação realizada neste estudo, porém, ressalta-se que o desbaste de $100 \%$ é mais viável, por aumentar o diâmetro das toras, concentrando desta forma para o segmento de serraria.

\subsection{Canal de laminação}

Adaptou-se o sistema para que as toras com diâmetros de $25 \mathrm{~cm}$ a $50 \mathrm{~cm}$ e com comprimento mínimo de $1,35 \mathrm{~m}$ pudessem ser direcionadas para o segmento de laminação. As madeiras que não atendessem estas medidas, mas que se 
enquadrassem na faixa de $15 \mathrm{~cm}$ a $50 \mathrm{~cm}$ de diâmetro e com comprimento a partir de $2,4 \mathrm{~m}$, poderiam ser direcionadas para o beneficiamento em serrarias. As madeiras que não atendessem estas medidas exclusivas das serrarias, mas que possuíssem de $8 \mathrm{~cm}$ a $40 \mathrm{~cm}$ de diâmetro e um comprimento mínimo de $1,2 \mathrm{~m}$, enquadrar-se-iam para a fabricação de celulose. Já aquelas que não atendessem nenhuma destas especificações seriam destinadas à geração de energia.

Os resultados da simulação indicam uma única rotação no vigésimo primeiro ano utilizando a densidade de 1.111 mudas com espaçamento de $3 \mathrm{~m} \times 3 \mathrm{~m}$. Após a determinação do período do ciclo e da densidade, identificou-se que o desbaste influencia significativamente no aumento do diâmetro para este segmento. No entanto, quanto mais intenso for o desbaste menor será a produtividade em $\mathrm{m}^{3}$ da floresta.

$\mathrm{Na}$ tentativa de maximizar a produtividade no canal de laminação, foram testadas escalas de desbaste diferentes das pré-definidas. A que gerou o melhor resultado foi a com desbaste seletivo de $63,10 \%$ no nono ano, extraindo o equivalente a 701 árvores.

O incremento corrente anual no nono ano é de $38,5 \mathrm{~m}^{3}$ de madeira, inferior ao incremento médio dos anos anteriores de $39,2 \mathrm{~m}^{3}$. No entanto, com o desbaste de 701 árvores, o ICA aumentou para $77 \mathrm{~m}^{3}$ no décimo ano e reduziu para $21,90 \mathrm{~m}^{3}$ no décimo primeiro ano. Esta oscilação de produtividade acontece porque as árvores cortadas iniciarão uma brotação, gerando novos metros cúbicos de madeira naquele ano.

O corte final no vigésimo primeiro ano proporciona $396,80 \mathrm{~m}^{3}$ de madeira, podendo ser direcionados $214,30 \mathrm{~m}^{3}$ para laminação; $144,10 \mathrm{~m}^{3}$ para serraria; $34,40 \mathrm{~m}^{3}$ para a fabricação de celulose; e $4 \mathrm{~m}^{3}$ para a geração de energia.

Embora nessa simulação pretendeu-se maximizar a produtividade no segmento laminação, grande parte da madeira ficou concentrada no segmento serraria, pois são poucas as árvores que alcançaram as especificações para processos de laminação.

\subsection{Resultados comparativos}

Para o canal de energia pode-se inserir 2.038 mudas por hectare de terra, com espaçamento de $3 \mathrm{~m} \times 1,6 \mathrm{~m}$, com rotações de sete anos cada e sem a realização de 
desbastes. Com essas especificações a produtividade poderá alcançar $1.023,50 \mathrm{~m}^{3}$ de madeira, sendo direcionada na sua totalidade para a geração de energia.

Comparando as especificações do canal de energia com o canal de celulose, percebe-se diferenciação quanto à densidade e espaçamento. A produtividade do canal de celulose é de $928,00(59,50+868,50) \mathrm{m}^{3}$, onde, $868,50 \mathrm{~m}^{3}$ poderão ser destinados para a fabricação de celulose e $59,50 \mathrm{~m}^{3}$ para a geração de energia, pois não alcançaram o diâmetro mínimo aceito neste canal.

Comparando o canal de serraria com o canal de celulose, constata-se que a única especificação diferente está nas rotações. Para maximizar a produção da madeira para serraria deve-se realizar uma rotação com dez anos e outra com onze anos. A sua produtividade poderá ser de $991,70(45,30+290,60+655,80) \mathrm{m}^{3}$, sendo, $655,80 \mathrm{~m}^{3}$ destinados para serraria, $290,60 \mathrm{~m}^{3}$ para celulose e $45,30 \mathrm{~m}^{3}$ para energia, por não alcançarem o diâmetro mínimo aceito neste setor.

Já para atender a fabricação de lâminas de eucaliptos, o produtor deverá inserir 1.111 mudas por hectare, com espaçamento de $3 \mathrm{~m} \times 3 \mathrm{~m}$. Necessitará realizar um desbaste no nono ano, retirando $63,10 \%$ da base, e uma única rotação no vigésimo primeiro ano. Assim, a produtividade poderá chegar a 600,20 $(12,70+77,10+296,10+$ $214,30) \mathrm{m}^{3}$, sendo $214,30 \mathrm{~m}^{3}$ destinados a laminação e $296,10 \mathrm{~m}^{3}, 77,10 \mathrm{~m}^{3}$ e $12,70 \mathrm{~m}^{3}$, destinados a serraria, celulose e energia, respectivamente, por não terem diâmetro aceito neste setor.

Os dados de custos de produção e da produtividade, por canal, são os elementos-chave para a análise da viabilidade econômica que segue na próxima seção.

\section{VIABILIDADE ECONÔMICA}

Nesta seção apresentam-se os resultados da projeção do fluxo de caixa. O cálculo da viabilidade econômica requer a utilização dos custos e das receitas, com a especificação das épocas de ocorrência. Estes serão submetidos a uma taxa de desconto, denominada custo de oportunidade do capital. Inicialmente, descreve-se a adoção da taxa de desconto do fluxo de caixa e do preço de comercialização da 
madeira. Logo após, apresenta-se o fluxo de caixa da produção de madeira de eucaliptos atendendo a diferentes canais de comercialização, com seus respectivos VPLs, VPLGs e taxas internas de retorno (TIR) resultante.

As entradas e as saídas retratadas no fluxo de caixa foram cotadas a preços correntes. Desse modo, para descontar as saídas e as entradas de caixa no período do investimento, utilizou-se como custo do capital a taxa de 9,38\% ao ano. Essa taxa refere-se à média aritmética do rendimento diário da caderneta de poupança de 01/09/00 a 31/08/05, divulgada pela Fundação Getúlio Vargas (FGV). Esta taxa líquida é facilmente obtida pelo produtor de madeira, pessoa física, em aplicações financeiras.

As cotações de preços de comercialização de madeira de eucaliptos no Rio Grande do Sul foram obtidas no IBGE, sendo a média comercializada na Região Sul do Brasil. O eucalipto para a geração de energia está cotado em $R \$ 38,000^{3}$, posto fábrica ou beira de estrada. Para a fabricação de celulose o produtor recebe $R \$ 50,00$ por $\mathrm{m}^{3}$ de eucalipto descascado posto fábrica. A madeira para beneficiamento nas serrarias tem um valor de mercado de $R \$ 90,00 \circ \mathrm{m}^{3}$ posto fábrica. Já o eucalipto que atende as medidas para o segmento laminação tem um preço de mercado de $R \$$ 110,00 posto fábrica.

A seguir apresenta-se o fluxo de caixa da produção de eucaliptos com o objetivo de direcionar a madeira para os canais de energia, celulose, serraria e laminação.

\subsection{Canal de energia}

Esse planejamento possui uma densidade de 2.038 mudas, com um espaçamento de $3 \mathrm{~m} \times 1,60 \mathrm{~m}$, com a realização de três rotações e sem a aplicação de desbastes. Tal observação se faz necessária, pois, cada canal tem uma estrutura de custos própria condizente com a densidade.

O fluxo de caixa 3 apresentado na Figura 2 foi elaborado de forma a permitir a avaliação do fluxo de caixa em cada um das três rotações de sete anos cada e do fluxo dos três períodos. O período zero é o período do investimento inicial, onde incidem os

\footnotetext{
${ }^{3}$ Representa-se o fluxo de caixa em uma linha do tempo, apresentando os valores que entram e saem do caixa cotados em moeda nacional, submetidos a uma taxa de desconto base para apurar o VPL, o VPLG e a TIR .
} 
custos de preparo do terreno (i); os custos de plantio (ii). O custo de assistência técnica (iii) tem incidência em todos os anos do planejamento, inclusive no ano zero.

Os tratos culturais (iv) que ocorrem nos primeiros dois anos de cada rotação têm um custo mais representativo na segunda e na terceira rotação do que a primeira. Isso ocorre porque quando termina uma rotação, é preciso realizar a adubação dos tocos, eliminar os outros vegetais existentes no solo, combater as formigas e selecionar os melhores brotos que surgirão para que a próxima rotação tenha o melhor desempenho possível. Ainda, nos tratos culturais do segundo ano da segunda e terceira rotação, é realizada a segunda desbrota para selecionar os melhores brotos que permanecerão até o final da rotação.

O cálculo da receita (v) foi processado com a obtenção da respectiva produtividade do canal de energia, descrita na seção anterior, multiplicado pelo preço médio da madeira de eucaliptos para este segmento cotado em $R \$ 38,00$, descrito no início deste capítulo. A realização da receita ocorre no final de cada rotação onde a madeira é vendida. Em cada ano de venda da madeira são desembolsados valores para cortar e baldear (vi).

Como este estudo considera que a madeira deveria ser entregue posto fábrica, o transporte deverá ser pago (vii). Os valores do transporte representados no fluxo foram calculados multiplicando a produtividade da respectiva rotação pelo custo do transporte em $\mathrm{m}^{3}$, para a distância de $50 \mathrm{~km}$. No final do projeto, considera-se a destoca, denominada de fluxo de caixa residual (viii), para deixar o terreno com condições de ser submetido a qualquer outro investimento. 


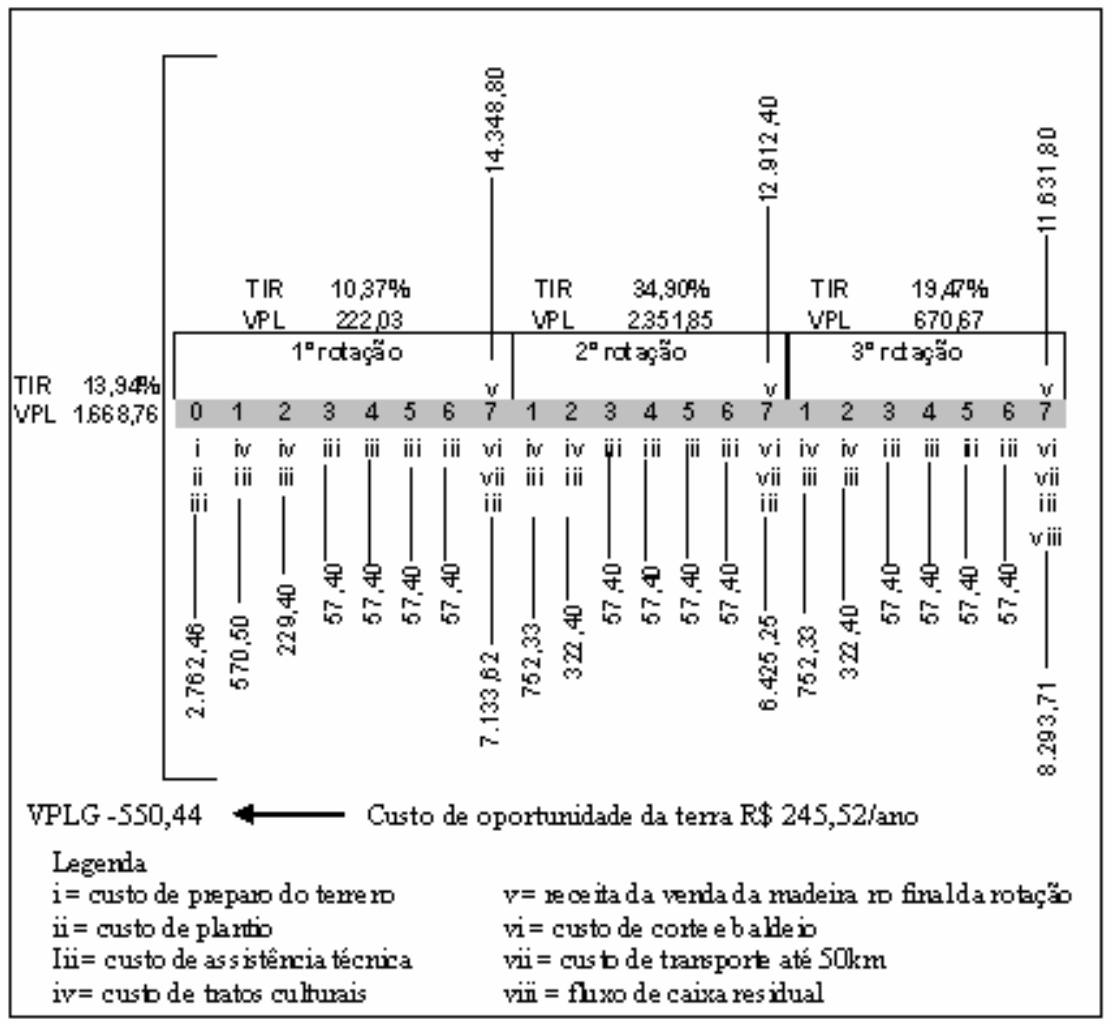

Figura 2: Fluxo de caixa da produção de eucaliptos, em Reais por hectare, atendendo o canal de energia, com três rotações de sete anos cada, no RS - 2005

Fonte: Dados da pesquisa

Taxa de desconto de $9,38 \%$ ao ano.

Observa-se na Figura 2 que os VPL's das rotações têm significativas diferenças de resultado. A produtividade de $377,60 \mathrm{~m}^{3}, 339,80 \mathrm{~m}^{3}$ e $306,10 \mathrm{~m}^{3}$, respectivamente, para as três primeiras rotações não foi a variável que influenciou na redução do resultado. Porém, o elevado custo do investimento inicial, incidente na primeira rotação, e o elevado custo de destoca, incidente na terceira rotação, contribuíram para os respectivos VPL's reduzidos.

O VPL da primeira rotação indica que o produtor está ganhando $R \$ 222,03 /$ ha a mais do que a taxa de desconto do capital de 9,38\% a.a. Na segunda rotação esse resultado é de $R \$ 2.351,85 /$ ha e na terceira rotação reduz para $R \$ 670,67 /$ ha. O VPL de todo o período informa que o produtor estaria ganhando $R \$ 1.668,76$ /ha a mais do que se tivesse investido o capital em uma instituição financeira que pagasse $9,38 \%$ a.a. 
No entanto, se for computado o custo de oportunidade da terra ( $R \$ 2.219,20)$, conforme descrito na seção 1 ter-se-ia um prejuízo com essa atividade, representado pelo VPLG negativo de $\mathrm{R} \$ 550,44$.

A representação da TIR de 10,37 \% a.a, identifica que a taxa de retorno acima do custo do capital na primeira rotação é de $0,99 \%(10,37-9,38)$. Se o VPL fosse zero, a TIR seria exatamente $9,38 \%$, sendo o fator de desconto do capital neste estudo. No entanto, como o VPL é positivo em $\mathrm{R} \$ 222,03$ a TIR deve obrigatoriamente ser superior ao custo de oportunidade do capital, sendo representada em $10,47 \%$ ao ano. A TIR de todo o projeto é de $13,94 \%$, exatamente $4,56 \%(13,94-9,38)$ a mais do que o custo do capital.

Como o VPL calculado computava o custo do transporte de apenas $50 \mathrm{~km}$, realizou-se uma análise de sensibilidade dos VPL's por distâncias da plantação até a sede compradora. A rentabilidade desse investimento se reduz muito quando se aumenta a distância de plantação em relação à sede compradora, conforme pode ser visualizado na figura 34.

${ }^{4}$ Essa figura e as demais semelhantes a essa, que seguem nessa seção, apresentam o VPL e o custo de oportunidade da terra o que permite ao leitor avaliar o retorno do investimento com e sem o custo de oportunidade da terra e a sua participação no total do retorno. 


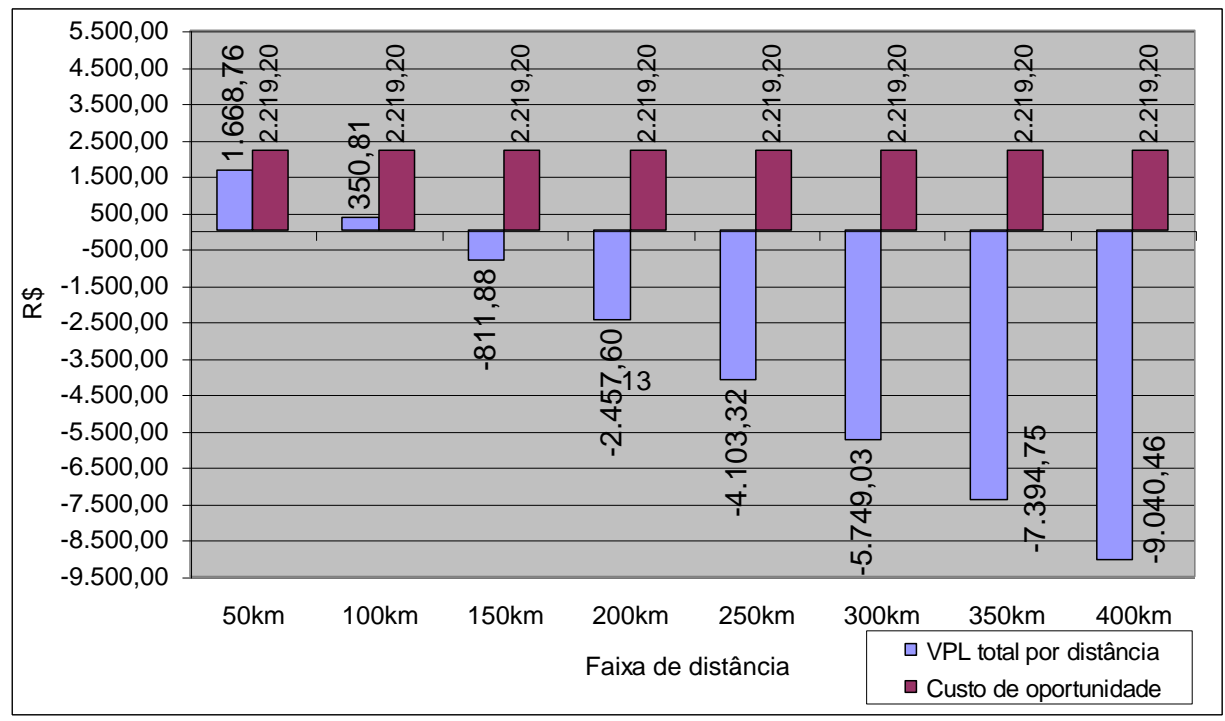

Figura 3: Viabilidade econômica da produção de eucaliptos, em Reais, destinada ao canal de energia, por distância do produtor ao consumidor, para o período de 21 anos, no RS - 2005

Fonte: Dados da pesquisa

Analisando os dados da Figura 3, verifica-se que os produtores que estiverem em uma distância de $50 \mathrm{~km}$ da sede compradora poderão obter um VPL de $R \$$ $1.668,76 /$ ha e que esse valor não cobre o custo de oportunidade da terra, situado em $\mathrm{R} \$ 2.219,20 / \mathrm{ha}$. Aqueles produtores que estiverem a uma distância acima de $100 \mathrm{~km}$ da sede compradora terão prejuízo contábil se realizarem o investimento. Ressalta-se que a rentabilidade da produção de eucaliptos para a geração de energia não cobre o custo de oportunidade da terra em nenhuma faixa de distância analisada, ou seja, considerando o VPLG o canal de energia gera prejuízo em qualquer situação. Considerando somente o VPL, existe "lucro" para aquelas produções que estão localizadas até $100 \mathrm{~km}$ da sede compradora.

Seguindo a mesma estrutura desta subseção, apresenta-se a seguir a viabilidade da produção de eucaliptos para os demais canais.

\subsection{Canal de celulose}

O cálculo do VPL e do VPLG utiliza o resultado ótimo do processo de simulação, que apresentava uma densidade de 1.666 mudas, com um espaçamento de $3 \mathrm{~m} \times 2 \mathrm{~m}$, com a realização de três rotações e sem a aplicação de desbastes, cujos custos foram 
detalhados na Seção 1. O custo de adubação, plantio, adubação de cobertura e adubação no primeiro ano, da produção de eucaliptos para celulose, é menor do que da produção para energia por ter uma densidade menor.

Ressalta-se que a madeira para celulose tem o custo de $\mathrm{R} \$ 6,38$ por $\mathrm{m}^{3}$ a mais do que as outras modalidades, pois necessita ser entregue descascada na fábrica. Logo, os $\mathrm{m}^{3}$ 's que não tem o diâmetro mínimo aceito para celulose $(8 \mathrm{~cm})$, serão destinados a geração de energia e não necessitarão de descasca, uma vez que se fosse realizado prejudicaria a combustão da madeira para esta finalidade.

A produção destinada para celulose é comercializada ao preço de $R \$ 50,00$ o m ${ }^{3}$ e a destinada à geração de energia ao preço de $\mathrm{R} \$ 38,00$. Apresenta-se o fluxo de caixa (Figura 4) da mesma forma que o apresentado anteriormente para o canal de energia.

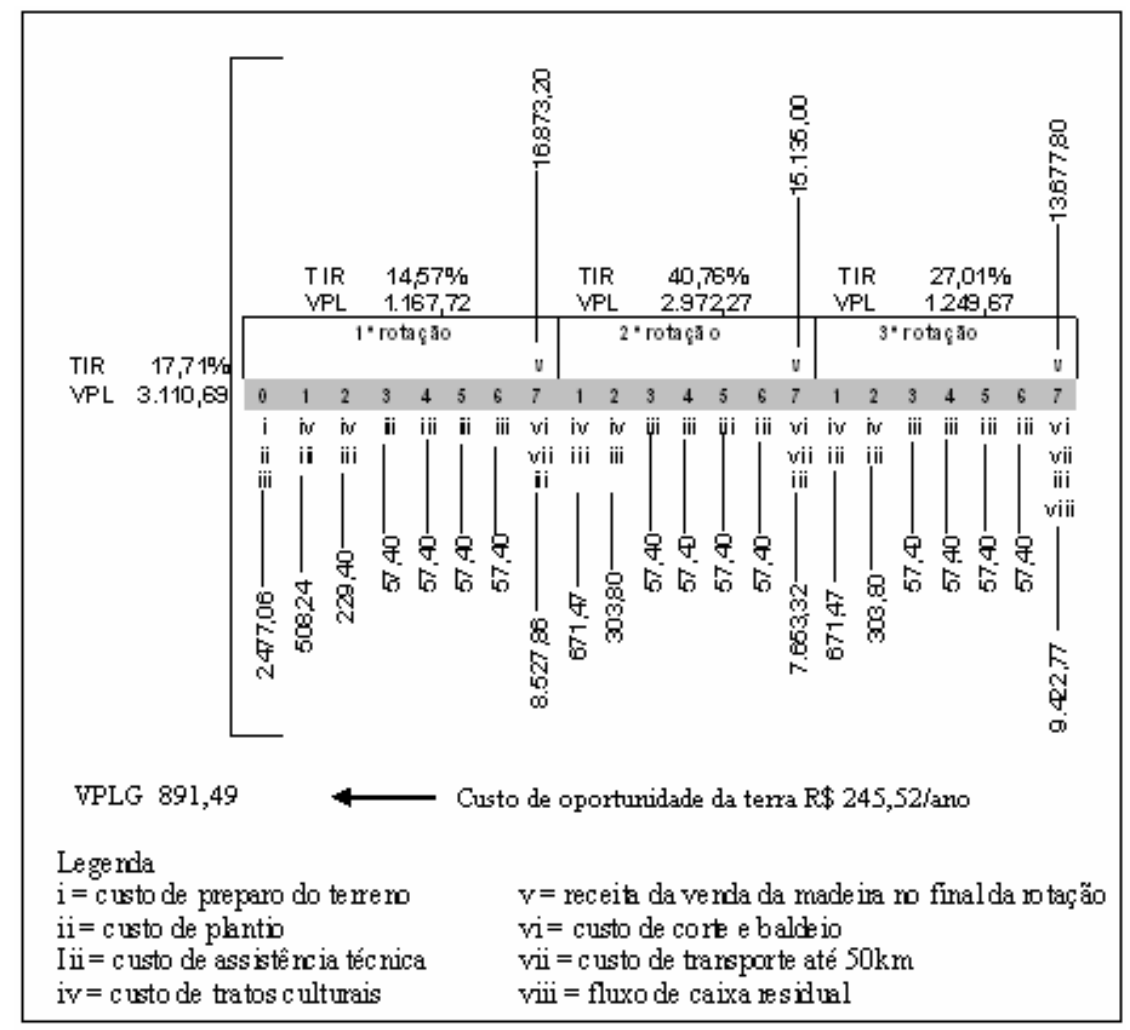

Figura 4: Fluxo de caixa da produção de eucaliptos, em Reais, para um hectare, atendendo o canal de celulose, com três rotações de sete anos cada, no RS - 2005

Fonte: Dados da pesquisa

Taxa de desconto de 9,38\% ao ano 
Observa-se na Figura 4 que os VPL's das rotações do canal de celulose também têm significativas diferenças no resultado. A mesma regra se aplica ao canal de celulose quanto ao custo de capital do investimento contribuir para a redução do VPL na primeira rotação e do custo de destoca reduzir o VPL da terceira rotação.

Embora a quantidade total de $\mathrm{m}^{3}$ produzido no canal de celulose seja menor que o produzido no canal de energia, os resultados dos seus VPL's são maiores. Isso se deve ao fato do preço do $\mathrm{m}^{3}$ de madeira para celulose ser maior do que o de energia, $\mathrm{e}$ pelo fato do custo de produção no canal de celulose ser menor por utilizar uma densidade menor.

Como pode ser verificado na Figura 4, o VPL da segunda rotação é o maior dos três, pois neste período as únicas saídas de caixa serão para pagar os tratos culturais e a assistência técnica.

Com base no resultado do VPL total do investimento, os produtores localizados na faixa de distância de até $50 \mathrm{~km}$ da fábrica estarão ganhando $R \$ 3.110,69 /$ ha se produzirem eucaliptos para atender o canal de celulose. Conforme a TIR, o retorno do investimento é de $17,71 \%$, a.a, o equivalente a $8,33 \%(17,71-9,38)$ a mais do que se tivessem investido o capital em uma instituição financeira que pagasse $9,38 \%$ a.a.

Para esse canal o VPLG passa a ser positivo, no valor de $\mathrm{R} \$ 891,49$. Ou seja, mesmo considerando o custo de oportunidade da terra ainda é vantajoso realizar o investimento, para propriedades localizadas até $50 \mathrm{Km}$ da fábrica de celulose.

A análise de sensibilidade dos VPL's por distância da plantação até a sede compradora comparado com o custo de oportunidade da terra para o período de 21 anos pode ser verificada na Figura 5. 


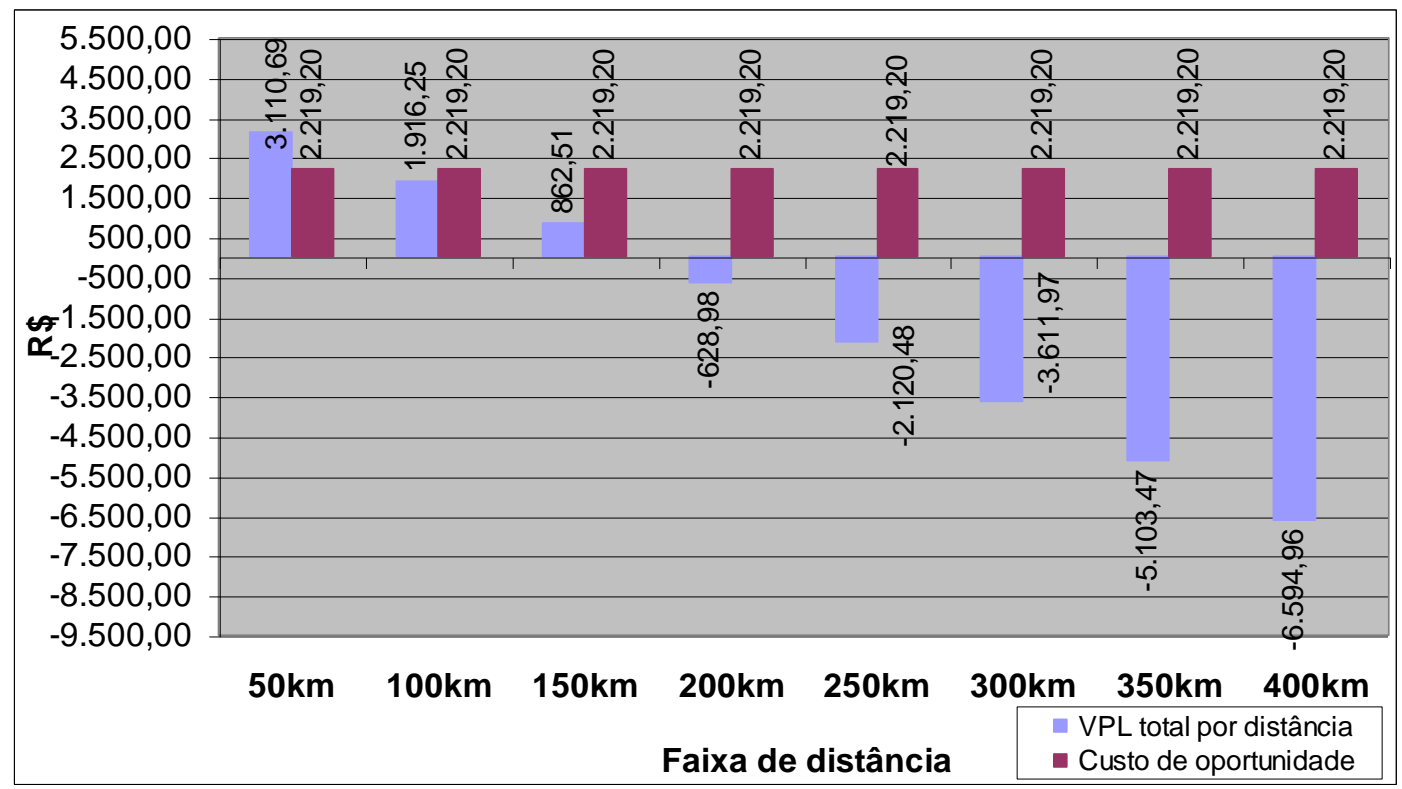

Figura 5: Viabilidade econômica da produção de eucaliptos, em Reais, destinada ao canal de celulose, por distância do produtor ao consumidor, para o período de 21 anos, no RS - 2005

Fonte: Dados da pesquisa

Analisando a Figura 5, verifica-se que os produtores que estiverem em uma distância de até $50 \mathrm{~km}$ da sede compradora obterão um VPL de $R \$ 3.110,69 /$ há, e que este valor cobre o custo de oportunidade da terra de $R \$ 2.219,20$. Para os produtores que estiverem na faixa de distância de $100 \mathrm{~km}$ a $150 \mathrm{~km}$ da fábrica, a produção gera lucro contábil, mas não cobre o referido custo de oportunidade. Após $200 \mathrm{Km}$ os investimentos em reflorestamento não deveriam ocorrer, pois não cobrem nem mesmo os gastos específicos realizados.

\subsection{Canal de serraria}

Esse cálculo considera a densidade de 1.666 mudas, com um espaçamento de $3 \mathrm{~m} \times 2 \mathrm{~m}$, com duas rotações e sem a aplicação de desbastes, conforme custos descritos anteriormente. O custo utilizado para essa modalidade (adubação, plantio, adubação de cobertura e adubação no primeiro ano), é o mesmo da produção de eucaliptos para celulose, por utilizar a mesma densidade. A diferenciação está no custo da desrama que será realizada no segundo ano de cada rotação, com duas freqüências, uma no início e outra no fim do mesmo ano. 
O cálculo da receita foi realizado com a obtenção da respectiva produtividade do canal de serraria multiplicado pelo preço médio da madeira de eucaliptos para serraria que é de $R \$ 90,00$ o m3. A madeira que não alcançou o diâmetro mínimo foi redirecionada para o canal de celulose ou de energia conforme dados anteriores. $\mathrm{O}$ fluxo de caixa pode ser visualizado na Figura 6.

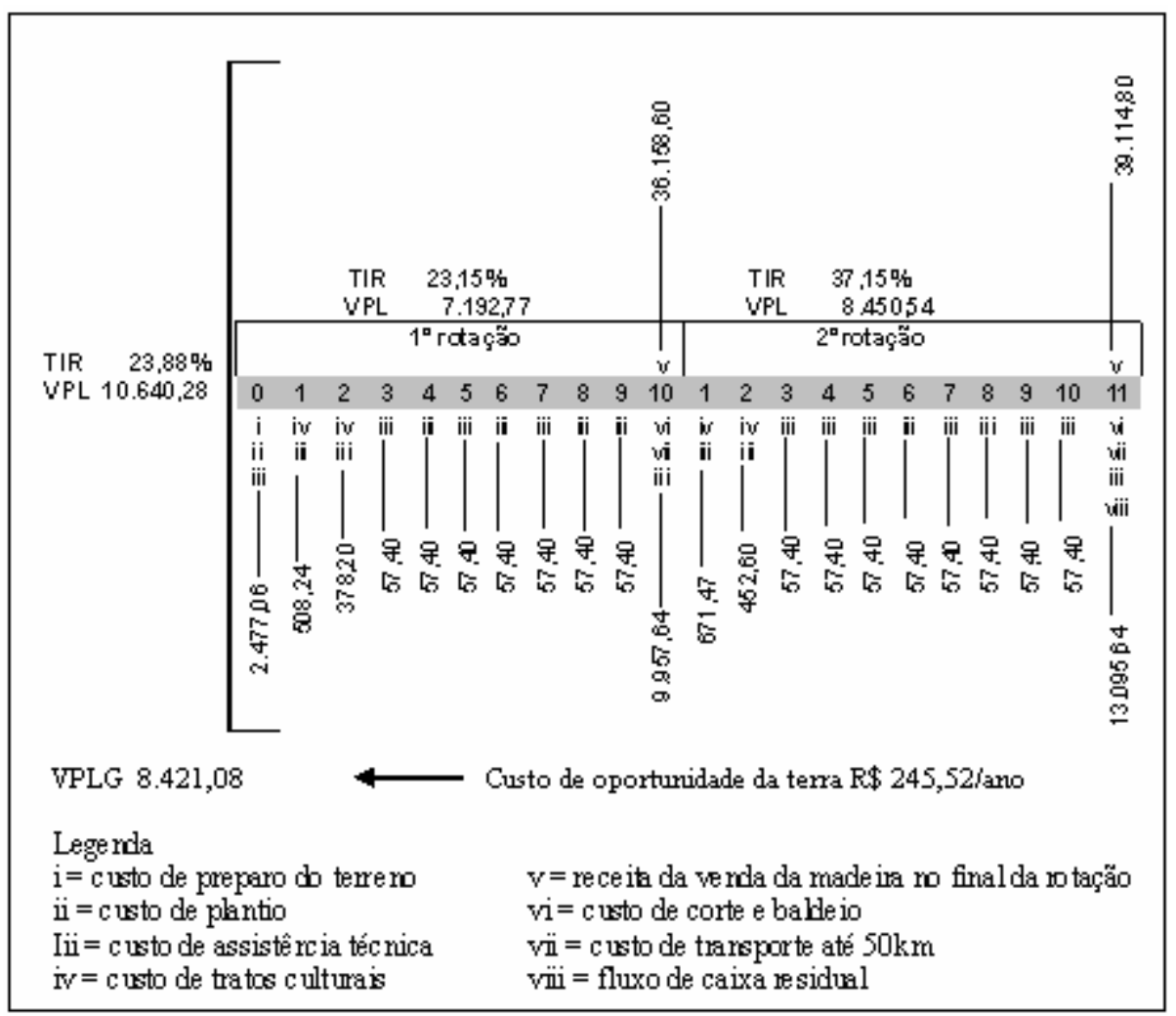

Figura 6: Fluxo de caixa da produção de eucaliptos, em Reais, para um hectare, atendendo o canal de serraria, em rotações de 10 e 11 anos cada, no RS - 2005

Fonte: Dados da pesquisa

Observa-se na Figura 6, que o VPL da segunda rotação é o que oferece o maior retorno entre as rotações. Isso ocorre porque a segunda rotação produz $33,50 \mathrm{~m}^{3} \mathrm{de}$ madeira $(512,60$ - 479,10) a mais do que a primeira, por ter um período maior. No que se refere ao VPL total, verifica-se que o investimento trará um retorno de $R \$$ $10.640,28 /$ ha. Representando o VPL em percentual, a TIR foi de $23,88 \%$, o equivalente a $14,50 \%(23,88-9,38)$ a mais do custo do capital. 
Já em relação ao VPLG, verifica-se que esse canal gera o maior valor, que é de $R$ \$ $8.421,08$. Considerando-se apenas a avaliação de taxa de retorno ou dos VPL e VPLG, aqueles que tivessem interesse em investir em reflorestamento de eucaliptos teriam nesse canal o melhor resultado financeiro.

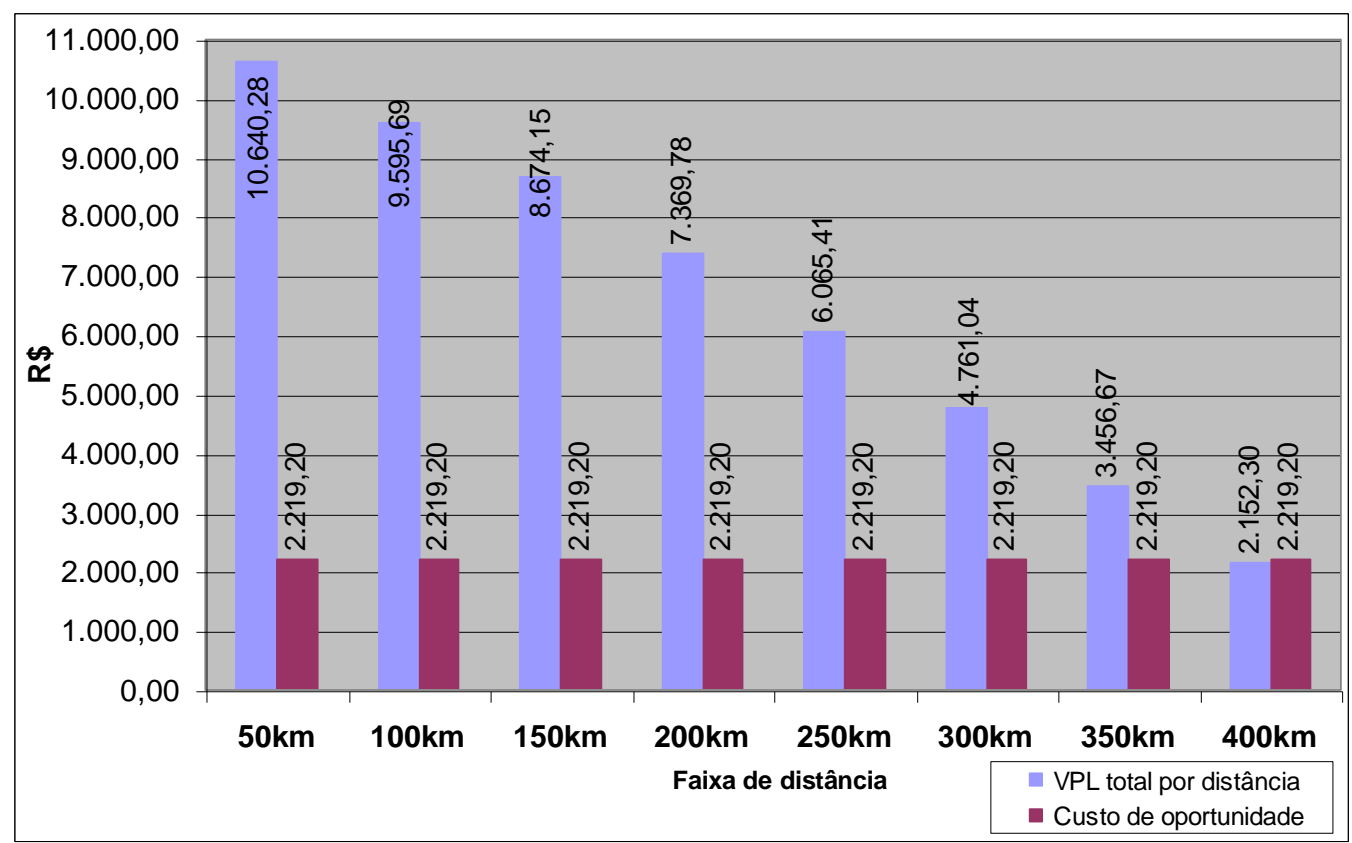

Figura 7: Viabilidade econômica da produção de eucaliptos, em Reais, destinada ao canal de serraria, por distância do produtor ao consumidor, para o período de 21 anos, no RS - 2005

Fonte: Dados da pesquisa

É interessante ressaltar que para esse canal, a rentabilidade ocorre até $350 \mathrm{Km}$ de distância da empresa compradora. A Figura 7 contém os valores dos VPL's por distância da plantação até a sede compradora e o custo de oportunidade da terra para o período de 21 anos.

\subsection{Canal de laminação}

Esse planejamento possui uma densidade de 1.111 mudas, com um espaçamento de $3 \mathrm{~m} \times 3 \mathrm{~m}$, com uma única rotação no vigésimo primeiro ano, conforme custos descritos na Tabela 9. Para a maximização da produtividade deverá ser realizado um desbaste no nono ano de $63,10 \%$ da base, removendo 701 árvores. 
O cálculo da receita foi realizado com a obtenção da respectiva produtividade do canal de laminação multiplicado pelo preço da madeira de eucaliptos para esse canal, de $R \$ 110,00$ posto na fábrica.

Para maximizar a produtividade no canal de laminação é necessário realizar duas desramas no segundo ano, sendo uma no início e outra no final do ano. O fluxo de caixa desse canal pode ser visualizado na Figura 8.

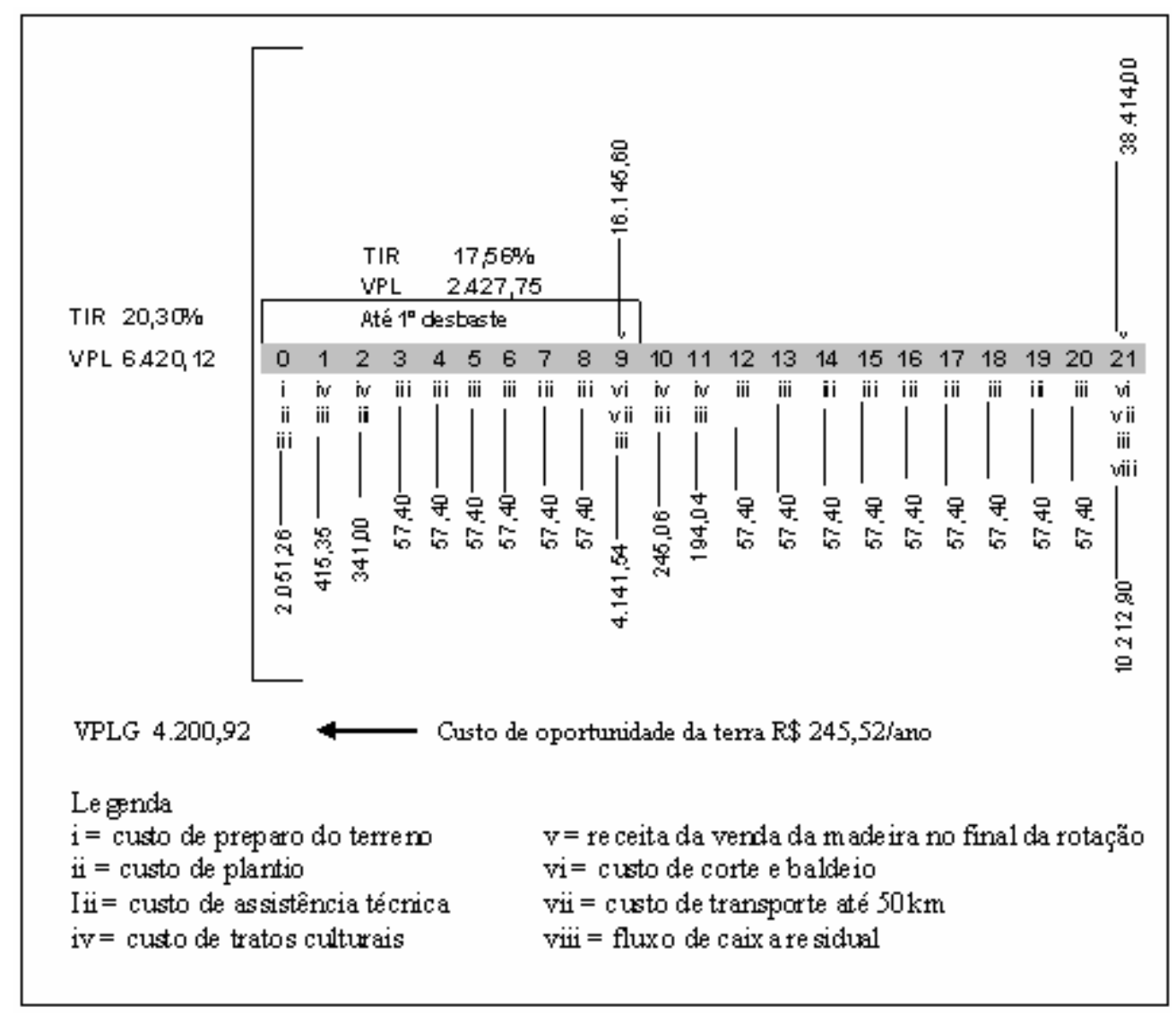

Figura 8: Fluxo de caixa da produção de eucaliptos, em Reais, atendendo o canal de laminação, em uma rotação de 21 anos, no RS - 2005

Fonte: Dados da pesquisa

O custo da produção por hectare para atender o canal de laminação é menor em relação à serraria por utilizar uma densidade menor. Outro fator de relevância para o canal de laminação é que o preço pago por $\mathrm{m}^{3}$ é maior do que nos demais canais.

No entanto, o VPL total de $R \$ 6.420,12 /$ ha é menor em relação ao VPL de $R \$$ $10.640,28$ /ha obtido na modalidade serraria. Isto ocorre porque a produção no canal de 
serraria é de $991,70 \mathrm{~m}^{3}$ e no de laminação a produção é de $600,20 \mathrm{~m}^{3}$, ou seja, $391,50 \mathrm{~m}^{3}$ a menos. Esta perda de produtividade ocorre porque é necessário ganhar maior diâmetro nas toras e para isso o seu corte é tardio. O VPLG resultou no elevado valor de $R \$ 4.200,92$, porém inferior ao do canal de serraria.

No nono ano deverá ser realizado um desbaste de $63,10 \%$ da base, o equivalente a 701 árvores, para que as árvores restantes tenham mais espaço e fotossíntese favorecendo o aumento de diâmetro. A receita obtida na realização do desbaste foi suficiente para cobrir as saídas de caixa e o investimento inicial, conforme evidenciado pelo VPL de $\mathrm{R} \$ 2.427,75 / \mathrm{ha}$.

Com base na Figura 8, verifica-se que a TIR obtida neste investimento é de $20,30 \%$ a.a, o equivalente a $10,92 \%(20,30$ - 9,38) a mais do que o custo de oportunidade do capital.

Na Figura 9 é apresentado o VPL do desbaste e do investimento por distância do produtor ao consumidor.

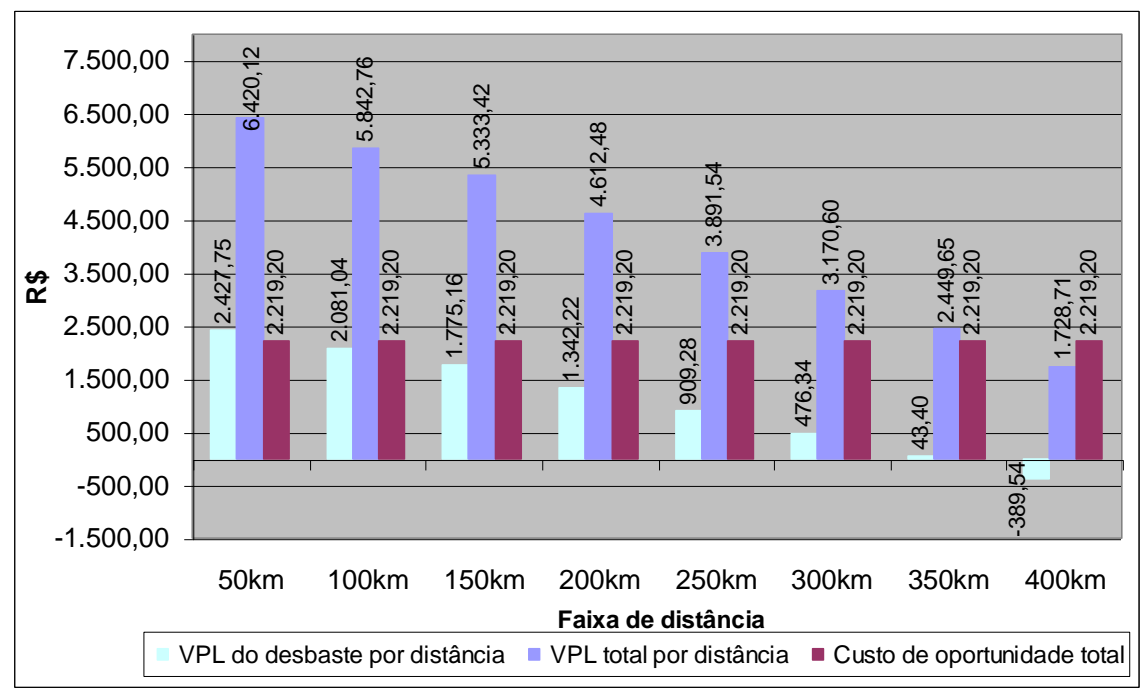

Figura 9: Viabilidade econômica da produção de eucaliptos, em Reais, destinada ao canal de laminação, por distância do produtor ao consumidor, para o período de 21 anos, no RS - 2005 Fonte: Dados da pesquisa.

Verifica-se que a viabilidade será superior ao custo de oportunidade da terra até a distância de $350 \mathrm{~km}$ do produtor ao consumidor. Já para a faixa de distância de 
$400 \mathrm{~km}$, a receita obtida com o desbaste de 701 árvores não será suficiente para cobrir os custos com corte e transporte.

Sintetizando os resultados obtidos para o cálculo do VPL, tem-se que a produção de eucaliptos para atender o canal de energia não apresentará, em nenhuma faixa de distância analisada, rentabilidade superior ao custo de oportunidade da terra.

Já na produção direcionada para o canal de celulose, obter-se-á rentabilidade superior àquele custo de oportunidade somente para a distância analisada de $50 \mathrm{~km}$. Tem-se, assim, que a produção de madeira para o canal de serraria é a que apresenta o maior retorno.

\section{CONCLUSÃO}

Analisando os custos de produção, verificou-se que a atividade de maior custo é a destoca, seguida do plantio, tratos culturais e preparo do terreno. De todos esses, o preparo do terreno e a destoca não variam por densidade.

No que se refere à produtividade, foi possível concluir que para o canal de energia, os melhores resultados foram obtidos com uma densidade de 2.038 mudas, inseridas em um espaçamento de $3 \mathrm{~m} \times 1,60 \mathrm{~m}$, sem a aplicação de desbastes com três rotações de sete anos cada uma. A produtividade total foi de $1.023,50 \mathrm{~m}^{3}$, que puderam ser direcionados para a geração de energia.

Para atender ao segmento de celulose, a densidade ideal foi de 1.666 mudas com espaçamento de $3 \mathrm{~m} \times 2 \mathrm{~m}$, três rotações de sete anos cada uma e sem desbastes. A produtividade total gerada foi de $928 \mathrm{~m}^{3}$, sendo direcionados $868,50 \mathrm{~m}^{3}$ para a fabricação de celulose e $59,50 \mathrm{~m}^{3}$ para a geração de energia por não terem alcançado o diâmetro mínimo do segmento.

No atendimento do canal de serraria, obteve-se como maximização a mesma densidade do canal de celulose e o mesmo espaçamento, sem aplicação de desbastes com duas rotações, sendo a primeira no décimo ano e a segunda no décimo primeiro ano. A produtividade total foi de $991,70 \mathrm{~m}^{3}$, sendo destinados $655,80 \mathrm{~m}^{3}$ para serraria, e $290,60 \mathrm{~m}^{3}$ e $45,30 \mathrm{~m}^{3}$ redirecionados para a fabricação de celulose e geração de 
energia, respectivamente, por não alcançarem o diâmetro mínimo aceito para serem vendidos no canal de serraria.

No que tange à produtividade para atender ao canal de laminação, o planejamento com uma densidade de 1.111 mudas, com um espaçamento de $3 \mathrm{~m} \times 3 \mathrm{~m}$, com uma única rotação no vigésimo primeiro ano, teve maior desempenho. A produtividade gerada foi de $600,20 \mathrm{~m}^{3}$, sendo direcionados $214,30 \mathrm{~m}^{3}$ para o canal de laminação e $296,10 \mathrm{~m}^{3}, 77,10 \mathrm{~m}^{3}$ e $12,70 \mathrm{~m}^{3}$ redirecionados, respectivamente, para os canais de serraria, celulose e energia, por não alcançarem o diâmetro mínimo desse setor.

Com base no estudo, verifica-se que a produção de eucaliptos para atender o canal de energia, não gera lucro econômico (retorno acima do custo de oportunidade da terra) em nenhuma faixa de distância analisada. A partir da distância de $100 \mathrm{~km}$ da fábrica apresenta prejuízo contábil. Identificou-se, também, que a primeira e a terceira rotação trazem uma rentabilidade inferior ao da segunda $e$ isso decorre fundamentalmente da necessidade de investimento inicial e o fluxo de caixa residual.

A produção de eucaliptos para atender o canal de celulose apresenta viabilidade econômica superior ao custo de oportunidade da terra somente para a produção que estiver na faixa de distância de até $50 \mathrm{~km}$ da fábrica e apresenta lucro contábil até a distância de $150 \mathrm{~km}$; a partir dessa distância gera prejuízo contábil.

$\mathrm{Na}$ busca da rentabilidade de cada rotação do canal de celulose, descobriu-se que a primeira rotação não alcança viabilidade superior ao custo de oportunidade da terra do respectivo período, em nenhuma faixa de distância analisada. A baixa rentabilidade da primeira rotação pode influenciar o produtor a não continuar com as próximas.

Por sua vez, tanto a produção atendendo o canal de serraria quanto laminação apresentam viabilidade superior ao custo de oportunidade da terra até a distância de $350 \mathrm{~km}$, sendo serraria o segmento que alcançou a maior viabilidade. Porém, destacase que nele a realização da receita ocorre somente a partir do décimo ano após o plantio. 
Em resumo, o canal que apresentou maior retorno foi o canal de serraria com um VPL de $R \$ 10.640,28 /$ ha e VPLG de $R \$ 8.421,08$ para uma distância de até $50 \mathrm{~km}$ e uma TIR de $23,88 \%$ a.a. O canal com o menor retorno foi o de energia, apresentando 0 VPLG negativo para qualquer distância e um VPL de $R \$ 1.668,76 /$ ha para uma distância de até $50 \mathrm{~km}$ e uma TIR de 13,94\% a.a.

\section{REFERÊNCIAS}

AMBIENTE BRASIL. Manejo de reflorestamento. Disponível em: <http://www.ambientebrasil.com.br/manejo.htm> Acesso em: 04/ago/2005.

ANDA - ASSOCIAÇÃO NACIONAL PARA DIFUSÃO DE ADUBOS. (1991). Acidez do solo e calagem. Boletim técnico oㅜ 1. São Paulo.

ARACRUZ, - Aracruz Celulose S/A. Negócios - mercado - vendas. Disponível em <http://www.Aracruz.com.br/negocios.htm>. Acesso em 28/fev/2005.

\section{Guaíba.} .(2005). Aracruz Celulose S/A. Dados de custos e de produtividade.

EMATER/RS - EMPRESA DE ASSISTÊNCIA TÉCNICA E EXTENSÃO RURAL. (2005). Informações técnicas. Passo Fundo.

EMBRAPA - EMPRESA BRASILEIRA DE PESQUISA AGROPECUÁRIA. (2005). Informações técnicas. Passo Fundo.

EMBRAPA - EMPRESA BRASILEIRA DE PESQUISA AGROPECUÁRIA. (2005). Software Siseucalipto. Curitiba.

EMPOFLOR - EMPRESA DE OPERAÇÕES FLORESTAIS. (2005). Informações sobre serviços. Porto Alegre.

FERTIBRAS. (2005). Informações sobre produtos. Santa Catarina. Dezembro. Disponível em: http://www.fertibras.gov.br/produtos/mirex-s.htm. Acesso em: 10/dez/2005.

FESSEL, Vitor A. (2003). Qualidade, desempenho operacional e custos de plantio, manual e mecanizado, de eucaliptos grandis implantados com cultivo mínimo de solo. (Dissertação de mestrado). São Paulo. ESALQ/USP. 
FGV - FUNDAÇÃO GETÚlIO VARGAS. (2005). Séries gratuitas: preços agropecuários. Rio de Janeiro. Disponível em: http://www.fgvdados.fgv.gov.br. Acesso em: 30/junho/2005.

HOFFMANN, Rodolfo et al. (1991). Estatística para economistas. São Paulo: Pioneira.

KARMEL, P.H., POLASEK, M. (1973). Estatística geral e aplicada à economia. São Paulo: Atlas.

IBGE - INSTITUTO BRASILEIRO DE GEOGRAFIA E ESTATÍSTICA. (2005). Banco de dados agregados: silvicultura. Passo Fundo. Disponível em: http://www.sidra.ibge.gov.br/. Acesso em 05/junho/2005.

INTELOG. (2008). Aracruz mantém investimento previsto para o RS. Porto Alegre. Disponível em: http://www.intelog.net/site/default.asp?TroncolD=907492\&SecaolD $=508074 \&$ Subsecao $\mid \mathrm{D}=818291 \&$ Template $=$. ./artigosnoticias/user_exibir.asp \&ID $=073382 \&$ Titulo $=A$ racruz\%20mant\%E9m\%20investimento\%20previsto\%20para\%200\%20RS. Acesso em: 03/set/2008.

OLIVEIRA, A. D, et al. (2002). Avaliação econômica da regeneração da vegetação de cerrados, sob diferentes regimes de manejo. Revista da árvore, vol. 26. Viçosa, nov/dez.

REFLORESTADORA NATIVA. (2005). Informações sobre serviços. Porto Alegre, Ago.

SOUZA, Álvaro N. et al. (2001). Momento ótimo de substituição de povoamentos de eucaliptos spp - o caso da tecnologia constante. Minas Gerais. Cerne, v7, n2, p. 093103.

REVISTA DA MADEIRA. RS recebe US\$ 3,6 bilhões em investimentos. Revista da Madeira, n. 94, ano 16, Fevereiro de 2006. Caxias do Sul. Disponível em: $\mathrm{http}: / / \mathrm{www} \cdot$ remade.com.br/pt/revista_materia.php?edicao $=94 \& \mathrm{id}=855$. Acesso em: 03/set/2008.

STJERNBERG, E. I. (1991). Planter productivity in prepared and unprepared ground: a case study. Feric Technical Note, n.162. Aug.

URCAMP - UNIVERSIDADE REGIONAL DA CAMPANHA. (2005). Reflorestar é preservar. Jun.

Data de Submissão: 04/10/2009 Data de Aceite: 23/03/2010 